\title{
Review Article \\ Progress in ZnO Acceptor Doping: What Is the Best Strategy?
}

\author{
Judith G. Reynolds ${ }^{1}$ and C. Lewis Reynolds ${ }^{2}$ \\ ${ }^{1}$ Department of Physics, North Carolina State University, Raleigh, NC 27695, USA \\ ${ }^{2}$ Department of Materials Science and Engineering, North Carolina State University, Raleigh, NC 27695, USA
}

Correspondence should be addressed to C. Lewis Reynolds; lew_reynolds@ncsu.edu

Received 13 November 2013; Revised 23 April 2014; Accepted 23 April 2014; Published 22 May 2014

Academic Editor: Jianrong Qiu

Copyright (C) 2014 J. G. Reynolds and C. L. Reynolds. This is an open access article distributed under the Creative Commons Attribution License, which permits unrestricted use, distribution, and reproduction in any medium, provided the original work is properly cited.

\begin{abstract}
This paper reviews the recent progress in acceptor doping of $\mathrm{ZnO}$ that has been achieved with a focus toward the optimum strategy. There are three main approaches for generating p-type $\mathrm{ZnO}$ : substitutional group IA elements on a zinc site, codoping of donors and acceptors, and substitution of group VA elements on an oxygen site. The relevant issues are whether there is sufficient incorporation of the appropriate dopant impurity species, does it reside on the appropriate lattice site, and lastly whether the acceptor ionization energy is sufficiently small to enable significant p-type conduction at room temperature. The potential of nitrogen doping and formation of the appropriate acceptor complexes is highlighted although theoretical calculations predict that nitrogen on an oxygen site is a deep acceptor. We show that an understanding of the growth and annealing steps to achieve the relevant acceptor defect complexes is crucial to meet requirements.
\end{abstract}

\section{Introduction}

Although zinc oxide has been investigated for many years, its potential for photonic and electronic applications has led to significant resurgence in interest during the last decade. Its use as a widely diverse functional material is enhanced by the fact that it can be grown in bulk, thin film, and nanostructures, examples of the latter being nanowires, nanobelts, and other morphologies that are dependent upon growth conditions. Although bulk substrates are readily available, $\mathrm{ZnO}$ thin films can also be grown heteroepitaxially across the misfit scale via the paradigm of domain matching epitaxy $[1,2]$. This is relevant for fabrication of next generation devices in which multiple functionalities are integrated on a given substrate. Potential applications of $\mathrm{ZnO}$ are blue/UV LEDs and lasers, photodetectors, transparent thin film transistors, transparent conducting oxides, gas sensors, and nanostructured piezoelectric nanogenerators, and substantial markets have been predicted. Many of the potential device applications, however, require both donor and acceptor doping, and growth of reproducible and stable p-type $\mathrm{ZnO}$ has been difficult to achieve. This doping asymmetry problem in which n-type doping is easily achieved while p-type is quite problematic is well known [3], and thus widespread development of $\mathrm{ZnO}$-based devices has been inhibited. For this special issue on structural, electronic, and optical properties of functional metal oxides, we do not intend to provide an exhaustive review of $\mathrm{ZnO}$ materials and devices as many review articles [3-9] have already been published but instead to focus on recent progress in acceptor doping in $\mathrm{ZnO}$ and to provide our assessment of the strategies pursued thus far.

Zinc oxide is a wide band gap semiconductor that typically crystallizes in the hexagonal wurtzite structure with a $3.37 \mathrm{eV}$ band gap at $300 \mathrm{~K}$ that is comparable to $\mathrm{GaN}$, both of which are suitable for UV and blue photonic devices. Zinc oxide also has several other characteristics that make it an attractive semiconducting material. As a consequence of its less than ideal $c / a=\sqrt{(8 / 3)}=1.633$ ratio in the $\mathrm{ZnO}$ wurtzite structure and tetrahedral coordination, it exhibits spontaneous polarization along the $c$-axis, the strength of which is related to the deviation from ideality. Strains in thin film heterostructures can also give rise to an additional piezoelectric polarization. On the basis of the Pauling electronegativity scale, the $\mathrm{Zn}-\mathrm{O}$ bond has a significant, $60 \%$, ionic nature instead of being considered a covalent compound. Furthermore, substitution of $\mathrm{Mg}$ or $\mathrm{Cd}$ 
ions on the $\mathrm{Zn}$ cation sublattice enables band gap tuning above and below the nominal $3.37 \mathrm{eV}$ band gap for growth of heterostructures. Advantages that $\mathrm{ZnO}$ has in comparison to $\mathrm{GaN}$ are availability of a native substrate, relative ease of wet chemical etching for device fabrication, its large exciton binding energy of approximately $60 \mathrm{meV}$ [10] and biexciton binding energies on the order of the $25 \mathrm{meV}$ thermal energy at room temperature [11]. These latter characteristics make it attractive for low threshold and large differential quantum efficiency photonic devices in the UV and blue portion of the electromagnetic spectrum. While current microelectronic, nanoelectronic, and optoelectronic devices are based on the flow of electric charge, integration of true multifunctionality on a chip will only be achieved when the spin of the electron can also be taken into consideration. Spin of the electron can be manipulated by an applied magnetic field and has relatively long relaxation times, which implies that devices can be smaller, use less energy, and provide logic operations. Zinc oxide has been predicted to exhibit ferromagnetic behavior at room temperature via a hole-mediated exchange mechanism [12], and thus stable p-type behavior is a requirement for successful demonstration of $\mathrm{ZnO}$ spintronics in electronic and photonic applications. While the above points to the significant promise of $\mathrm{ZnO}$-based devices, two major issues must be resolved: high defect densities and doping asymmetry. The former is readily addressed by fabrication of $\mathrm{ZnO}$-based structures that have been grown homoepitaxially. As stated above, however, the doping asymmetry problem is the dominant issue that limits $\mathrm{ZnO}$-based materials and devices.

There are three fundamentally different approaches for growth of p-type $\mathrm{ZnO}$ : substitution of Group IA impurities, for example, $\mathrm{Li}, \mathrm{Na}$, or $\mathrm{K}$ on a $\mathrm{Zn}$ site, substitution of Group VA impurities such as N, P, As, and Sb on the O site, and codoping with donors and acceptors. It is clear that the successful approach will be that which enables substantial p-type conduction at room temperature; that is, the acceptor ionization energy must be relatively shallow and compensation by background impurities and/or defects must be minimized. Here, we attempt to summarize the recent accomplishments that have been achieved via each of these methods and to assess the trends in order to postulate what we believe to be the optimum strategy for both thin film heterostructures and nanostructures. Below, we will first address the origin of background donors, which is highly dependent upon whether the material is grown in a $\mathrm{Zn}$ rich or an O-rich environment, the role of $\mathrm{H}$ as a donor in $\mathrm{ZnO}$, and the issue of the acceptor ionization energy of substitutional $\mathrm{N}$ on the $\mathrm{O}$ sublattice. We follow this with a summary of recent reports on the p-type behavior for the various potential doping schemes and then conclude with our outlook.

\section{Origin of Background Donors in $\mathrm{ZnO}$}

In order to be able to achieve the high $\left(>10^{17} \mathrm{~cm}^{-3}\right)$ acceptor concentration necessary for useful p-type conductivity, the solid solubility of the acceptor impurity must be relatively high while the self-compensating defects and acceptor ionization energies must be low. Nominally undoped $\mathrm{ZnO}$ is ntype with carrier concentrations ranging from $10^{14}$ to mid$10^{16} \mathrm{~cm}^{-3}$. Traditionally, the underlying cause of the unintentional $n$-type conductivity has been assigned to the formation of zinc interstitials $\left(\mathrm{Zn}_{i}\right)$ and oxygen vacancies $\left(V_{\mathrm{O}}\right)$ [13]. Comprehensive calculations $[13,14]$ of the formation energies of dilute native point defects in $\mathrm{ZnO}$ via first principles density functional theory (DFT) within the local density approximation (LDA) $[15,16]$ have thus been performed. The pseudopotential plane-wave method [17] employed uses constant volume supercells and a pair potential approach. At equilibrium, the concentration, $c$, of a defect in the crystal lattice as a function of its formation energy, $E^{f}$, is as follows:

$$
c=N_{\text {sites }} \exp \left(-\frac{E^{f}}{k_{B} T}\right),
$$

where $N_{\text {sites }}$ is the concentration of sites in the crystal where the defect can occur and $k_{B}$ and $T$ are the Boltzmann constant and temperature, respectively. Hence, a low $E^{f}$ implies a high equilibrium concentration of the defect and a high $E^{f}$ means that defect formation is less likely to occur. Additionally, the formation energy $E^{f}$ of a point defect in a charge state $q$ is given by [13]

$$
E^{f}(q)=E^{\mathrm{tot}}(q)-n_{\mathrm{Zn}} \mu_{\mathrm{Zn}}-n_{\mathrm{O}} \mu_{\mathrm{O}}-q E_{F},
$$

where $E^{\text {tot }}(q)$ is the total energy of a system containing $n_{\mathrm{Zn}}$ and $n_{\mathrm{O}}$ zinc and oxygen atoms, $\mu_{\mathrm{Zn}}$ and $\mu_{\mathrm{O}}$ are the chemical potentials for zinc and oxygen, respectively; and $E_{F}$ is the Fermi energy. The chemical potentials depend upon the growth conditions. For high zinc partial pressure, $\mu_{\mathrm{Zn}}=$ $\mu_{\mathrm{Zn} \text { (bulk) }}$, while for high oxygen partial pressure, $\mu_{\mathrm{O}}=\mu_{\mathrm{O}_{2}}$. For intermediate II-VI ratios, $\mu_{\mathrm{Zn}}<\mu_{\mathrm{Zn} \text { (bulk) }}$ and $\mu_{\mathrm{O}}<\mu_{\mathrm{O}_{2}}$. Since $\mathrm{Zn}$ and $\mathrm{O}$ are in equilibrium within $\mathrm{ZnO}$, their chemical potentials are not independent necessitating $\mu_{\mathrm{Zn}}+\mu_{\mathrm{O}}<\mu_{\mathrm{ZnO}}$.

All native point defect formation energies in $\mathrm{ZnO}$ have been calculated [13]. Figure 1 summarizes the $E^{f}$ 's as a function of the Fermi energy $E_{F}$ [13] for zinc-rich conditions including those for octahedral $\mathrm{Zn}_{i}, \mathrm{Zn}$ antisites, $\mathrm{Zn}_{\mathrm{O}}$, and zinc vacancies $V_{\mathrm{Zn}}$, in various charge states. For oxygen-rich conditions, $E^{f}$ 's as a function of $E_{F}$ for octahedral $\mathrm{O}_{i}$, and $\mathrm{O}$ antisites, $\mathrm{O}_{\mathrm{Zn}}$, and $V_{\mathrm{Zn}}$ in various charge states are presented in Figure 2.

As the incorporation of donors or acceptors shifts the Fermi energy, spontaneous formation of these charged defects acts to compensate the prevailing conductivity in $\mathrm{ZnO}$. The formation energy of $\mathrm{Zn}_{i}$ across most of the Fermi level range is high making them an unlikely selfcompensating species in n-type material. However, in $\mathrm{p}$ type material, the formation energies for charged species, $\mathrm{Zn}_{i}{ }^{+1}$ and $\mathrm{Zn}_{i}{ }^{+2}$ are more favorable, but the strain energy introduced by the self-interstitial limits their concentration. The absence of the charged $V_{\mathrm{O}}{ }^{+}$and $V_{\mathrm{O}}{ }^{2+}$ species in the energy diagram in Figure 2 reflects their high formation energy near the conduction band minimum (CBM). Since the formation energy of $V_{\mathrm{O}}{ }^{+}$is always higher than either $V_{\mathrm{O}}{ }^{2+}$ 


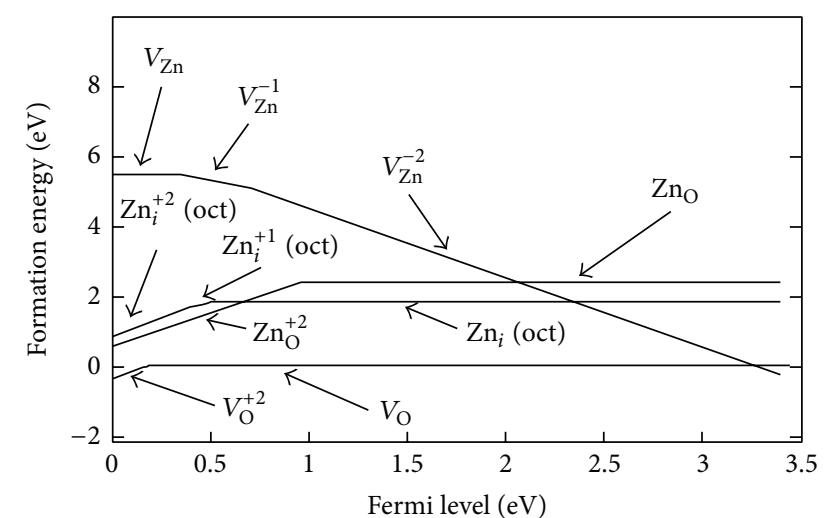

Figure 1: Calculated defect formation energy for selected defects as a function of the Fermi level and for $\mu_{\mathrm{Zn}}=\mu_{\mathrm{Zn}}{ }^{\mathrm{O}}$ (high zinc partial pressure). Only the lowest formation energy values are shown. The zero of the Fermi level is set to the top of the valence band. Reprinted with permission from [13]. Copyright 2000 by the American Physical Society.

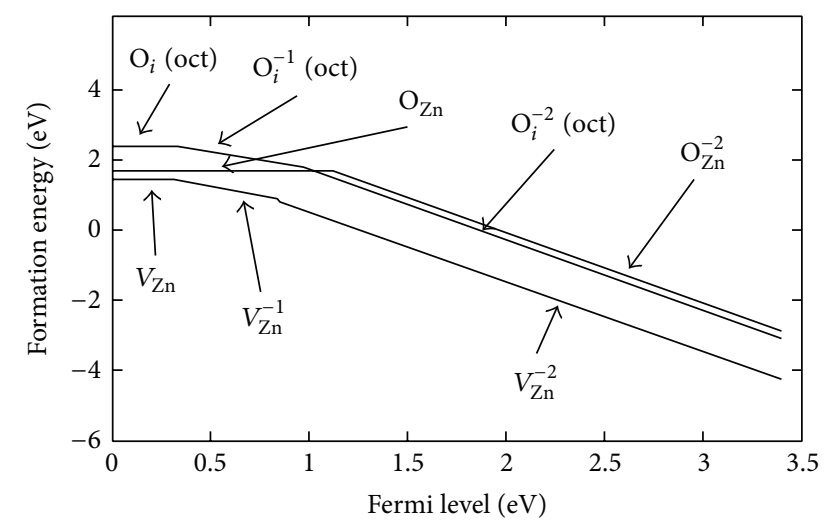

Figure 2: Calculated defect formation energy for selected defects as a function of the Fermi level and for $\mu_{\mathrm{Zn}}=\mu_{\mathrm{Zn}}{ }^{\mathrm{O}}+\Delta E_{f}^{\mathrm{ZnO}}$ (low zinc partial pressure). Only the lowest formation energy values are shown. The zero of the Fermi level is set to the top of the valence band. Reprinted with permission from [13]. Copyright 2000 by the American Physical Society.

or $V_{\mathrm{O}}$, the positive charge state is never thermodynamically stable [14]. However, by virtue of their low $E^{f}$ 's, $V_{\mathrm{O}}{ }^{2+}$ or $V_{\mathrm{O}}$ may be self-compensating species across the Fermi energy range.

Since hydrogen is unintentionally incorporated during MOVPE growth processes, it is also a plausible contributor to n-type conductivity in $\mathrm{ZnO}$ films. The formation energy of the hydrogen interstitial in charge state $q$ is defined by [14]

$$
E^{f}\left(\mathrm{H}^{q}\right)=E^{\text {tot }}\left(\mathrm{H}^{q}\right)-E^{\text {tot }}(\text { bulk })-\mu_{\mathrm{H}}+q E_{F},
$$

where $E^{f}\left(\mathrm{H}^{q}\right)$ is the total energy derived from a supercell calculation for the hydrogen interstitial, $E^{\text {tot }}$ (bulk) is the total energy for a supercell containing only bulk $\mathrm{ZnO}, \mu_{\mathrm{H}}$ is the hydrogen chemical potential, and $E_{F}$ is the Fermi level which is set to 0 at the top of the valence band [14]. Defect species $\mathrm{H}^{0}$ and $\mathrm{H}^{-}$are never stable in $\mathrm{ZnO}$ because they are at a much higher energy level in the band structure than

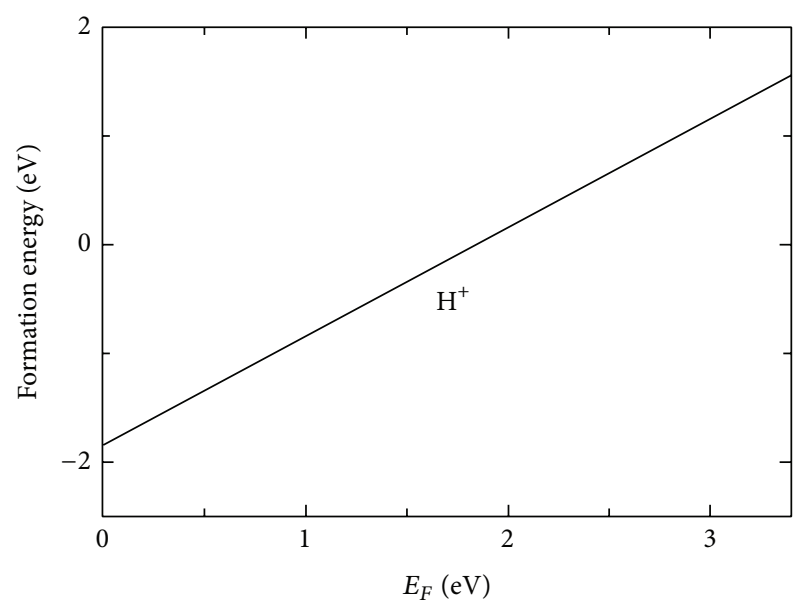

FIGURE 3: Formation energy of interstitial hydrogen in $\mathrm{ZnO}$ as a function of Fermi level, obtained from DFT-LDA calculations and referenced to the energy of a free $\mathrm{H}_{2}$ molecule. Zero-point energies are included. The zero of Fermi energy is chosen at the top of the valence band. Reprinted with permission from [14]. Copyright 2001 by Elsevier Science B.

$\mathrm{H}^{+}$[14]. The calculated formation energy for $\mathrm{H}^{+}$in $\mathrm{ZnO}$ is shown in Figure 3. The lowest energy position for $\mathrm{H}$ is at the bond-center $(\mathrm{BC})$ site with the antibonding $\left(\mathrm{AB}_{\mathrm{O}}\right)$ position slightly higher in energy [14]. When $H$ is at the $A B_{Z n}$ site, the corresponding state is localized near the $\mathrm{H}$ atom. When $\mathrm{H}$ is at the $\mathrm{BC}$ and $\mathrm{AB}_{\mathrm{O}}$ sites, the occupied state becomes an extended state because it is at a higher energy level [14].

The formation energy of interstitial $\mathrm{H}$ shows that the solubility of $\mathrm{H}^{+}$is higher under p-type conditions than under n-type conditions. While that may seem deleterious to accomplishing $\mathrm{p}$-type conductivity in $\mathrm{ZnO}$, hydrogen does have the beneficial effect of increasing acceptor solubility and suppressing compensation by native defects in $\mathrm{GaN}$ [18]. Also, since $\mathrm{H}^{+}$prefers positions where the charge density is high and it remains close to the donated electron [18], it may easily form complexes with double acceptor species resulting in single acceptor complexes. Additionally, $\mathrm{H}^{+}$can be removed from the $\mathrm{ZnO}$ lattice during high temperature post-growth anneals.

\section{Strategies for p-Type Doping}

As mentioned above, there are three primary different approaches that have been investigated to generate appreciable hole conduction in $\mathrm{ZnO}$ at room temperature: substitution of Group IA impurities on the $\mathrm{Zn}$ sublattice, codoping of donors and acceptors, and substitution of Group $\mathrm{VA}$ impurities on the $\mathrm{O}$ sublattice. And multiple growth techniques for thin films, for example, molecular beam epitaxy (MBE), magnetron sputtering, metalorganic vapor phase epitaxy (MOVPE), pulsed laser deposition (PLD), and sol-gel, have been utilized. In this section, we will address recent progress in each of these approaches. On the basis of Hall measurements that have been reported, it is clear that in general the hole concentrations are relatively low and 
TABLE 1: Summary of room temperature Hall data for p-type $\mathrm{ZnO}$.

\begin{tabular}{|c|c|c|c|c|c|c|}
\hline $\begin{array}{l}\text { Growth } \\
\text { technique }\end{array}$ & Structure $^{\mathrm{a}}$ & $\begin{array}{l}\text { Acceptor doping } \\
\text { scheme }\end{array}$ & $\begin{array}{l}\text { Hole concentration } \\
\quad\left(10^{18} \mathrm{~cm}^{-3}\right)\end{array}$ & $\begin{array}{c}\text { Mobility } \\
\left(\mathrm{cm}^{2} \mathrm{~V}^{-1} \mathrm{~s}^{-1}\right)\end{array}$ & $\begin{array}{l}\text { Resistivity } \\
(\Omega-\mathrm{cm})\end{array}$ & Reference \\
\hline CVD & $\mathrm{U}$ & $\begin{array}{c}\mathrm{NH}_{3} \text { and excess } \\
\mathrm{Zn}\end{array}$ & 0.015 & 12 & 34 & Minegishi et al. [19] \\
\hline MBE & SC & RF plasma $\mathrm{N}_{2}$ & 0.09 & 2 & 40 & Look et al. [20] \\
\hline $\begin{array}{l}\text { RF diode } \\
\text { sputtering }\end{array}$ & SC & Ga, N codoping & 0.09 & 6 & 11.77 & Singh et al. [21] \\
\hline $\begin{array}{l}\text { MBE (ECR O } \\
\text { source) }\end{array}$ & $\mathrm{U}$ & $\begin{array}{l}\text { Sb-doped }+ \\
800^{\circ} \mathrm{C} \text { anneal }\end{array}$ & 1.7 & 20 & 0.2 & Xiu et al. [22] \\
\hline $\begin{array}{l}\text { DC reactive } \\
\text { magnetron } \\
\text { sputtering }\end{array}$ & $\mathrm{PC}^{\mathrm{b}}$ & Li-doped & 0.14 & 2.65 & 16.4 & Zeng et al. [23] \\
\hline $\begin{array}{l}\text { RF magnetron } \\
\text { sputtering }\end{array}$ & SC & $\begin{array}{c}\text { Ga and } \mathrm{N} \\
\text { codoping }\left(\mathrm{N}_{2}\right. \\
\text { sputtering gas })\end{array}$ & 0.39 & 0.4 & 38 & Kumar et al. [24] \\
\hline $\begin{array}{l}\text { Plasma assisted } \\
\text { MOVPE }\end{array}$ & $\mathrm{U}$ & $\begin{array}{l}\mathrm{NO} \text { plasma as } \mathrm{O} \\
\text { and } \mathrm{N} \text { source }\end{array}$ & 2.29 & 1.59 & 1.72 & Zeng et al. [25] \\
\hline Sol-gel & $\mathrm{PC}$ & $\begin{array}{c}\mathrm{Al} \text { and } \mathrm{N} \\
\text { codoping }+\mathrm{O} \\
\text { anneal }\end{array}$ & $0.08-0.2$ & $1.6-1.73$ & $19-45$ & Dutta et al. [26] \\
\hline $\begin{array}{l}\text { RF magnetron } \\
\text { sputtering }\end{array}$ & SC & $\begin{array}{l}\mathrm{O} \text { and As dual } \\
\text { implantation }\end{array}$ & $6.8-19.8$ & $19-32.9$ & $0.05-0.55$ & Kim et al. [27] \\
\hline MOVPE & $\mathrm{U}$ & P-doped & 0.21 & 1.2 & - & Du et al. [28] \\
\hline PLD & PC & $\begin{array}{l}\text { Na-doped + } \\
254 \mathrm{~nm} \\
\text { illumination }\end{array}$ & 0.21 & 7.9 & 3.8 & Lin [29] \\
\hline PLD & SC & $\begin{array}{c}\mathrm{N}^{+} \text {implantation } \\
+ \text { dynamic } \\
\text { annealing }\end{array}$ & $0.024-0.52$ & $0.7-3.71$ & $18-71$ & Myers et al. [30] \\
\hline $\begin{array}{l}\text { Plasma assisted } \\
\text { MBE }\end{array}$ & $\mathrm{U}$ & $\begin{array}{l}\text { Sb-doped }+ \\
800^{\circ} \mathrm{C} \text { anneal }\end{array}$ & 0.06 & - & - & Huang et al. [31] \\
\hline MOVPE & SC & $\begin{array}{l}\text { As-doped via } \\
\text { outdiffusion }\end{array}$ & 0.35 & 0.79 & - & Shi et al. [32] \\
\hline $\begin{array}{l}\text { Magnetron } \\
\text { sputtering }\end{array}$ & $\mathrm{U}$ & $\begin{array}{c}\mathrm{P} \text { and } \mathrm{N} \\
\text { codoping }+ \\
800^{\circ} \mathrm{C} \text { anneal }\end{array}$ & 1.16 & 1.35 & 3.98 & Sui et al. [33] \\
\hline $\begin{array}{l}\text { Plasma assisted } \\
\text { MBE }\end{array}$ & SC & Na doping & 0.002 & 0.4 & 8575 & Ding et al. [34] \\
\hline Spin coating & $\mathrm{PC}$ & $\begin{array}{l}\mathrm{N}, \text { Al codoping } \\
+ \text { double anneal } \\
\text { in } \mathrm{NH}_{3} \text { and } \mathrm{N}_{2}\end{array}$ & 0.61 & 198.8 & 0.05 & Kalyanaranan et al. [35] \\
\hline MOVPE & SC & $3 \% \mathrm{NO}$ in $\mathrm{N}_{2}$ & 3.6 & 0.4 & 4.4 & Reynolds et al. [36] \\
\hline
\end{tabular}

${ }^{\mathrm{a}} \mathrm{U}$ : undefined; SC: single crystal; PC: polycrystalline. All are thin films.

${ }^{\mathrm{b}}(002)$ preferential orientation.

that mobility values indicate that the thin films are quite compensated. A summary of the recent data in chronological order is given in Table 1. The fundamental goal is significant p-type conduction at room temperature, which implies that one must achieve shallow acceptor ionization energies with minimal compensation by unintentional impurities and/or defects.

3.1. Group IA Li and Na on a Zinc Site. While Park et al. [37] have predicted $\mathrm{Li}$ and $\mathrm{Na}$ to exhibit relatively shallow, $\sim 0.1-0.17 \mathrm{eV}$, acceptor levels in $\mathrm{ZnO}$, a more recent hybrid density functional investigation [38] has shown the ionization energy to be $0.6-1.1 \mathrm{eV}$ above the valence band maximum, that is, becomes significantly deeper. The latter attributed this discrepancy to the well-known band gap error in DFT and its influence on the energy of the $\mathrm{Li}_{\mathrm{Zn}}$ acceptor level. As the band gap widens, the acceptor level shifts upward away from the VBM due to becoming more localized. However, there have been limited reports of successful acceptor behavior that is based on Group IA doping. Using DC reactive magnetron sputtering, Zeng et al. [23] have demonstrated hole concentrations of $\sim 10^{17} \mathrm{~cm}^{-3}$ at a growth 
temperature of $550^{\circ} \mathrm{C}$ in Li-doped thin films; however, the acceptor concentration decreases an order of magnitude as the growth temperature decreases or increases $50^{\circ} \mathrm{C}$ on either side of the optimum. They also suggest that $\mathrm{Li}_{\mathrm{Zn}}$ may be relatively unstable because of a higher Madelung energy. As we will see later, a lowered Madelung energy is suggested as being fundamental to understanding why codoping should result in p-type behavior. For $\mathrm{Na}$-doped $\mathrm{ZnO}$, p-type $\mathrm{ZnO}$ has been reported for thin films grown by PLD [29] and plasma assisted MBE [34]. In the former, it was suggested that absorbed $\mathrm{O}$ species at grain boundaries are deleterious to p-type behavior, and thus, it was necessary to subject films to $254 \mathrm{~nm}$ UV illumination to remove these species to obtain a p-type film. Nevertheless, they were able to achieve a mobility of $7.9 \mathrm{~cm}^{2} \mathrm{~V}^{-1} \mathrm{~s}^{-1}$ at a hole concentration of $2.1 \times 10^{17} \mathrm{~cm}^{-3}$, and the acceptor ionization energy was estimated to be $110 \mathrm{meV}$ from temperature-dependent Hall data. For the plasma assisted $\mathrm{MBE} \mathrm{ZnO}$, nonpolar a-plane films were grown on $r$-plane sapphire. The relatively low hole concentration of $\sim 2 \times 10^{15} \mathrm{~cm}^{-3}$ was attributed to compensation by oxygen vacancies. Such weak p-type behavior is not anticipated to yield substantial hole conduction at room temperature. In general, the low mobilities observed in these investigations indicate that the films are most likely compensated. Group IA elements are relatively reactive, and thus we expect that anomalous $\mathrm{p}-\mathrm{n}$ junction behavior may be an issue as observed for Group IIA dopants in traditional IIIV semiconductors.

3.2. Codoping of Donors and Acceptors. Performing ab initio electronic band structure calculations, Yamamoto and Katayama-Yoshida [39] showed that substitutional N-doping alone increases the Madelung energy resulting in localization of $\mathrm{N}$ states. They thus suggested that codoping with $\mathrm{Al}$ or $\mathrm{Ga}$ and $\mathrm{N}$ leads to energetically favorable acceptor-donoracceptor complexes that lead to a reduction in the Madelung energy with delocalized $\mathrm{N}$ states and equally important enhanced incorporation of $\mathrm{N}$ acceptors. More recent density functional theory calculations support this suggestion showing that codoping of $\mathrm{N}$ with $\mathrm{Al}$ or $\mathrm{Ga}$ leads to a strong attractive interaction between $\mathrm{Al}_{\mathrm{Zn}}$ or $\mathrm{Ga}_{\mathrm{Zn}}$ donors and nearest neighbor $\mathrm{N}_{\mathrm{O}}$ acceptors. Although (Al-2N) or (Ga$2 \mathrm{~N})$ complexes form at higher concentrations of nitrogen, their behavior is predicted to be quite different with regard to nitrogen solubility [40]. That is, Duan et al. [40] predicted enhanced nitrogen solubility when using NO as the nitrogen source and codoping with Ga and N, which should lead to improved p-type conductivity. However, the relatively weak interaction between $\mathrm{Al}$ and $\mathrm{N}$ and $\mathrm{N}$ on a substitutional $\mathrm{O}$ site suggested that $\mathrm{N}$ solubility is not enhanced via $\mathrm{Al}$ and $\mathrm{N}$ codoping. Furthermore, the estimated acceptor ionization energies are 0.17 and $0.14 \mathrm{eV}$ for $\mathrm{Al}$ and $\mathrm{Ga}$ codoped with $\mathrm{N}$, respectively, which is substantially less than their predicted ionization energy of $0.33 \mathrm{eV}$ for substitutional $\mathrm{N}_{\mathrm{O}}$ only. They have also shown that codoping with the transition metals (Zr, Ti, Y, and Sc) and nitrogen can lead to complexes with levels above the valence band maximum that indicate lower ionization energies than the isolated $\mathrm{N}$ acceptor [41].
Although codoping of donors and acceptors has been predicted to lead to improved p-type conduction via the presence of shallow acceptor levels in comparison to the isolated nitrogen on an oxygen site, experimentally, relatively low hole concentrations, $<\sim$ mid $-10^{17} \mathrm{~cm}^{-3}$, with low mobilities are observed (see Table 1) [21, 24, 26, 35]. Singh et al. [21] demonstrated p-type $\mathrm{ZnO}$ thin films for $(\mathrm{Ga}, \mathrm{N})$ codoped films grown by RF diode sputtering but found that the observation of p-type behavior depended upon the oxygen partial pressure to total pressure ratio. For films grown with less than $50 \%$ O partial pressure, $n$-type conduction was observed, but films grown with $50 \%$ and above exhibited p-type behavior that appeared to saturate at $60 \% \mathrm{O}$ partial pressure. P-type conduction was attributed to suppression of $V_{\mathrm{O}}$ and $\mathrm{Zn}_{i}$ and the associated compensation with codoping. In addition, films exhibiting p-type behavior revealed both (002) and (100) reflections in X-ray diffraction (XRD) patterns. Most likely, this is related to $\mathrm{N}$ incorporation in the films as we will discuss in the next section for substitutional $\mathrm{N}$ on an $\mathrm{O}$ site. They claim a reduction in band gap to $3.27 \mathrm{eV}$ for $\mathrm{p}$-type films; however, this emission peak is most likely related to an acceptor-related transition [21]. Using RF magnetron sputtering, Kumar et al. [24] have reported p-type behavior for (Ga, $\mathrm{N})$ codoped films grown on both sapphire and $\mathrm{Si}$ in which $\mathrm{N}_{2} \mathrm{O}$ was used as the sputtering gas. For films grown below $450^{\circ} \mathrm{C}$, conduction was n-type. At a growth temperature of $550^{\circ} \mathrm{C}$, they achieved a resistivity of $38 \Omega-\mathrm{cm}$ with a hole concentration of $3.9 \times 10^{17} \mathrm{~cm}^{-3}$. Somewhat puzzling though is the $1.3 \times 10^{19} \mathrm{~cm}^{-3}$ hole concentration reported for films grown on Si. In spite of the significant difference in misfit and thermal expansion coefficients between $\mathrm{ZnO}$ and sapphire and between $\mathrm{ZnO}$ and $\mathrm{Si}$ (see, e.g., [6]) and resultant defect densities, it is most likely that the high hole concentration is not representative of the film but is indicative of an issue with the Hall measurements on the p-type substrate. Although these authors claim that only (002) and (004) diffraction peaks are observed in the XRD spectra for films grown on both substrates, close examination of the spectrum on $\mathrm{Si}$ reveals a (101) $\mathrm{ZnO}$ reflection. As we will discuss in the next subsection, we believe that this reflection is associated with $\mathrm{N}$ incorporation in the film.

Other codoped films have utilized $(\mathrm{Al}, \mathrm{N})$ codoping and have been deposited via sol-gel [26] and spin coat [35] processes. Dutta et al. [26] reported that films that were only $\mathrm{N}$-doped exhibited mixed $\mathrm{n}$ and $\mathrm{p}$ conduction while the $\mathrm{Al}$ and $\mathrm{N}$ codoped films were stable p-type with hole concentrations of $(0.8-2) \times 10^{17} \mathrm{~cm}^{-3}$ that were dependent upon the $\mathrm{Zn} / \mathrm{N} / \mathrm{Al}$ ratios. All films were annealed in an oxygen ambient. While their undoped and solely $\mathrm{N}$-doped films were polycrystalline, their codoped (Al, N) ones exhibited a strong (002) diffraction peak with much weaker (100) and (101) peaks. We believe that presence of the latter weak reflection is related to $\mathrm{N}$ incorporation. Grain sizes were in the range $25-75 \mathrm{~nm}$. Although the $(\mathrm{Al}, \mathrm{N})$ codoped $\mathrm{ZnO}$ films grown by spin coating were polycrystalline with grain sizes $\sim 25 \mathrm{~nm}$, they exhibited reasonably high hole concentrations, $6 \times 10^{17} \mathrm{~cm}^{-3}$, and extraordinarily high mobility, $198.8 \mathrm{~cm}^{2} \mathrm{~V}^{-1} \mathrm{~s}^{-1}$ [35]. This is the highest mobility that we 
have seen reported for holes in $\mathrm{ZnO}$ and seems unreasonable considering the polycrystalline nature of the films. A $550^{\circ} \mathrm{C}$ anneal in $\mathrm{NH}_{3}$ served as the $\mathrm{N}$-dopant source, and films were subjected to another post-growth anneal at $700^{\circ} \mathrm{C}$ to remove $\mathrm{H}$. This last step is crucial as it has been suggested that $\mathrm{H}$ is the dominant donor in $\mathrm{ZnO}[42,43]$. Comparison of $\mathrm{Ga}$ and $\mathrm{N}$ versus $\mathrm{Al}$ and $\mathrm{N}$ codoped films enables one to make an interesting observation that seems counter to firstprinciples DFT calculations [40]. For (Ga, N) codoped films, the reported $[21,24]$ hole concentrations are in the range of $0.9-3.9 \times 10^{17} \mathrm{~cm}^{-3}$, whereas those $[26,35]$ codoped with $\mathrm{Al}$ and $\mathrm{N}$ are $0.8-6 \times 10^{17} \mathrm{~cm}^{-3}$; that is, there appears to be no significant difference between codoping with $\mathrm{Ga}$ or $\mathrm{Al}$ and $\mathrm{N}$ with regard to $\mathrm{N}$ dopant solubility and/or acceptor ionization energy. As mentioned in the beginning of this subsection, DFT calculations implied that Ga and N codoping should increase $\mathrm{N}$ solubility compared to $\mathrm{Al}$ and $\mathrm{N}$ codoping because the interaction between $(\mathrm{Al}-2 \mathrm{~N})$ and a neighboring $\mathrm{N}$ on an oxygen site is weak in comparison to that between two (Ga$\mathrm{N})$ complexes and the binding between $(\mathrm{Ga}-2 \mathrm{~N})$ and a nearest neighbor N [40]. A more recent investigation [44] on p-type conduction for $\mathrm{N}$ and $\mathrm{Te}$ codoped $\mathrm{ZnO}$ films has reinforced the proposed role [39] of codoping for generating p-type behavior; that is, N/Te codoping lowers the Madelung energy for enhanced $\mathrm{N}$ incorporation. However, it was necessary to subject the codoped films to a $700^{\circ} \mathrm{C} / 30 \mathrm{~min}$ anneal in an $\mathrm{O}_{2}$ environment in order to reduce donor-related defects and enable $\mathrm{n}$ - to p-type conversion in the films. However, the luminescence data are somewhat puzzling with regard to the relative importance of $\mathrm{N}_{2}$ flow and anneal related to the Hall data (see Figure 6 in Park et al. [44] in relation to carrier concentration data in Table 1). An added benefit of the thermal anneal step is that it improves crystal quality that had been degraded by codoping as evidenced by the increase in the FWHM of the (0002) X-ray reflection with increasing $\mathrm{N}_{2}$ flow. Their highest reported hole concentration of $1.6 \times$ $10^{16} \mathrm{~cm}^{-3}$ after the anneal occurred for the highest $\mathrm{N}_{2}$ flow and also exhibited a mobility of $1.8 \mathrm{~cm}^{2} \mathrm{~V}^{-1} \mathrm{~s}^{-1}$, the latter implying that the films are heavily compensated.

3.3. Group VA Elements on an Oxygen Site. Although the Group VA elements (N, P, As, and Sb) have predicted acceptor ionization energies greater than those of the Group IA elements on the zinc site, the Group VAs have been the most extensively investigated. Of the Group VA elements, nitrogen seems to be the most suitable because of its electronic structure, and its ionic radius, $0.168 \mathrm{~nm}$, is closer to that of oxygen, $0.138 \mathrm{~nm}$, than the other elements for which the ionic radii differences are $>50 \%$ [3]. One might anticipate that such a larger ionic radius compared to that of oxygen would introduce considerable strain into the wurtzite lattice. More importantly, the ionization energies are predicted to be $>\sim 1 \mathrm{eV}$ for $\mathrm{P}, \mathrm{As}$, and $\mathrm{Sb}$ [45]. However, an acceptor ionization energy of 197-227 meV has been reported for Sb-doped $\mathrm{ZnO}$ grown by MBE [22]. Substitutional nitrogen on an oxygen site alone is particularly interesting. Ionization energies of 0.33 [40], $0.4[37,46]$, and $1.3 \mathrm{eV}[47]$ have been predicted, none of which would be compatible with appreciable hole
TABLE 2: Reported acceptor ionization energies for Group VA elements on an oxygen site.

\begin{tabular}{lcc}
\hline Dopant & $E_{A}(\mathrm{meV})$ & Reference \\
\hline $\mathrm{N}$ & 100 & Minegisha et al. [19] \\
$\mathrm{N}$ & $170-200$ & Look et al. [20] \\
$\mathrm{N}$ & 165 & Myers et al. [30] \\
$\mathrm{N}$ & 209 & Wang and Giles [48] \\
$\mathrm{N}$ & 180 & Zeng et al. [25] \\
$\mathrm{N}$ & 160 & Stehr et al. [49] \\
$\mathrm{N}$ & 134 & Reynolds et al. [36] \\
$\mathrm{Sb}$ & $197-227$ & Xiu et al. [22] \\
\hline
\end{tabular}

conduction at room temperature. Nevertheless, on the basis of Hall measurements, p-type conduction has been reported for nitrogen and the other Group VA dopant elements. Reported ionization energies for $\mathrm{N}_{\mathrm{O}}$ are in the range of 100-200 meV (see Table 2 for a summary of the ionization energies). In view of these results, it seems clear that complexes involving nitrogen are mainly responsible for p-type behavior as we will discuss below. We begin first though with a brief summary of p-type conduction for P-, As-, and Sbdoped $\mathrm{ZnO}$. Recall that a summary of relatively recent room temperature Hall data are given in Table 1.

P-type behavior for P-doped $\mathrm{ZnO}$ has been reported for films grown by MOVPE [28] and magnetron sputtering [33]. In the latter reference, Sui et al. demonstrated that $\mathrm{P}$ and $\mathrm{N}$ codoping provided an order of magnitude increase to the hole concentration compared to P-doping alone. They attributed this to the addition of nitrogen to a neutral $\mathrm{P}_{\mathrm{Zn}^{-}}{ }^{-}$ $3 \mathrm{~N}_{\mathrm{O}}$ complex to form a $\mathrm{P}_{Z n}-4 \mathrm{~N}_{\mathrm{O}}$ acceptor complex, which gives rise to formation of an impurity band above the valence band maximum similar to the discussion above for donoracceptor codoping. Their optimum hole concentration of $1.16 \times 10^{18} \mathrm{~cm}^{-3}$ was achieved after a post-growth anneal at $800^{\circ} \mathrm{C}$ for $30 \mathrm{~min}$ at a pressure of $10^{-4} \mathrm{~Pa}$. The low mobility of $1.35 \mathrm{~cm}^{2} \mathrm{~V}^{-1} \mathrm{~s}^{-1}$ implies that the films are heavily compensated. Du et al. [28] confirmed their p-type Hall data with $C-V$ measurements and claimed their films to be stable for four months. Of particular relevance in the latter investigation is that they were able to demonstrate lasing under electrical pumping for a P-doped $\mathrm{p}-\mathrm{ZnO} / \mathrm{n}$ GaN heterostructure; the FWHM of the electroluminescence spectrum narrowed to $\leq 1 \mathrm{~nm}$ at $9 \mathrm{~mA}$ and above. However, other resistivity and luminescence data have suggested that phosphorous doping for p-type behavior in $\mathrm{ZnO}$ is more problematic. Von Wenckstern et al. [50] have grown P-doped $\mathrm{ZnO}$ heteroepitaxially and homoepitaxially and found quite varying results. For example, as-grown heteroepitaxial films were semi-insulating to n-type, whereas scanning capacitance microscopy of homoepitaxial films indicated regions of mixed carrier type; both results are consistent with the predictions of Park et al. [37], based on the amphoteric behavior of $\mathrm{P}$ in $\mathrm{ZnO}$.

As-doped films have been achieved via MOVPE [32] and $(\mathrm{O}, \mathrm{As})$ dual implantation [27] into a film that was grown by magnetron sputtering. In the former, Shi et al. [32] 
formed $\mathrm{p}-\mathrm{ZnO}$ by As outdiffusion from a neighboring GaAs layer. They reported a hole concentration of $3.56 \times 10^{17} \mathrm{~cm}^{-3}$, which was attributed to formation of an $\mathrm{As}_{\mathrm{Zn}}-2 \mathrm{~V}_{\mathrm{Zn}}$ complex, and also demonstrated electroluminescence from a p-n junction light emitting diode type structure based on As-doped ZnO. For the implanted films [27], mixed conduction was observed for As implantation alone, whereas dual implantation followed by an $800^{\circ} \mathrm{C}$ anneal in $\mathrm{N}_{2}$ resulted in hole concentrations $\sim 10^{19} \mathrm{~cm}^{-3}$ with relatively high hole mobilities that depended upon the fluence of As and O. The observation of hole conduction in As-doped $\mathrm{ZnO}$ however is contrary to the predictions of Park et al. [37], who based their analysis on the amphoteric nature of these dopants. In spite of the large ionic radii size difference between $\mathrm{Sb}$ and $\mathrm{O}$, hole conduction has been observed in Sb-doped $\mathrm{ZnO}[31,45]$. For the Group VA elements P, As, and Sb, Xiu et al. have reported the highest hole concentration, $1.7 \times 10^{18} \mathrm{~cm}^{-3}$, with a corresponding mobility of $20 \mathrm{~cm}^{2} \mathrm{~V}^{-1} \mathrm{~s}^{-1}$ for Sb-doped $\mathrm{ZnO}$ [22]. Their films were grown by MBE with elemental $\mathrm{Zn}$ and Sb sources and an oxygen plasma electron-cyclotron resonance source for the oxygen. Growth was followed by an $800^{\circ} \mathrm{C}$ in situ anneal; the hole concentration increased with the $\mathrm{Sb}$ effusion cell temperature. Huang et al. [31] used plasma assisted MBE to grow their films and also required an $800^{\circ} \mathrm{C}$ in situ anneal to activate their Sb. Earlier though, Friedrich et al. [51] reported a deterioration of the sample surface with an increase in the $\mathrm{Sb}$ concentration due to the increase in lattice stress. They claim that there is a tendency for Sb-O precipitate formation, which suppresses formation of $\mathrm{Sb}_{\mathrm{Zn}}-2 \mathrm{~V}_{\mathrm{Zn}}$ complexes for p-type behavior. More recently, it was demonstrated that the conduction type in Sb-doped $\mathrm{ZnO}$ depended upon the concentration of $\mathrm{Sb}$ in films grown by plasma enhanced MBE [52]. Liu et al. demonstrated that films with Sb concentrations in the doping regime (varied by changing the Sb flux) exhibited n-type behavior for electron concentrations in the $10^{16}$-mid- $10^{19} \mathrm{~cm}^{-3}$ range while films with $\sim 1$ at $\%$ Sb revealed compensating acceptor-like defects with a resultant decrease in electron concentration. It was suggested that $\mathrm{Sb}$ incorporates on the $\mathrm{Zn}$ site for relatively low Sb concentrations but the observed sudden increase in the $c$-lattice parameter suggested that $\mathrm{Sb}$ begins to reside on the $\mathrm{O}$ site at higher concentrations, $\sim 1$ at \% [52]. Structural degradation of the films was also observed to occur with increasing $\mathrm{Sb}$ as also reported by Friedrich et al. [51] above. Yankovich et al. [53] have reported that stable acceptor conduction is observed in Sb-doped $\mathrm{ZnO}$ nanowires in which $\mathrm{Sb}$ decorates basal plane inversion domain boundaries. This electron acceptor behavior was related to the phenomenon of $\mathrm{Sb}$ and $\mathrm{O}$ codoping and shown to be consistent with density functional theory calculations. This suggests however that acceptor behavior via Sb-doping is not necessarily simple formation of an isolated acceptor level but involves defect complexes within the material, which we believe to be the relevant mechanism for appreciable room temperature hole conduction.

There have been considerable calculations on substitutional Group VA impurities, mostly nitrogen, on the oxygen site. Although the magnitude of the ionization energies varies from 0.33 to $1.3 \mathrm{eV}$, all are consistent with a deep acceptor for a single $\mathrm{N}_{\mathrm{O}}$. This strongly suggests that the experimental observation of p-type conduction in $\mathrm{N}$-doped $\mathrm{ZnO}$ is predominantly related to complexes involving nitrogen. As mentioned above, Park et al. [37] performed first principles DFT calculations using the pseudopotential method within the LDA [15]. Since their calculations included a nonlinear partial core correction (NPC) [54], they gave a $2 x$ correction of the bandgap for $\mathrm{ZnO}$ compared to those that only included the $\mathrm{Zn}$-3d states as valence electrons. Their underestimate of the bandgap, $1.56 \mathrm{eV}$, is a characteristic error in the LDA approach and their $25 \%$ underestimate of the calculated heat of formation of $\mathrm{ZnO}$ follows. However, their calculations do reveal the trend for the increase in defect energy levels when Group VA elements are substituted on the O site compared to Group IA defects substituted on the $\mathrm{Zn}$ site. Since Group IA elements lack an active $d$ orbital, they have reduced $p-d$ coupling which lowers their defect energies. The higher defect energy levels for Group VA elements are a result of increasing impurity $p$-orbital energy from $\mathrm{N} \rightarrow \mathrm{P} \rightarrow$ As [37]. The key point revealed by their calculations was the importance of AX centers, which are deep defect complexes that compensate for acceptors. The positive energy required to form positively charged AX centers from the substitutional acceptors on a $\mathrm{Zn}$ site indicates that Group IA elements are only metastable in $\mathrm{ZnO}$ [37]. The negative energy for Group VA elements, $\mathrm{P}$ and As, means they are more stable as AX centers than substitutional states on the $\mathrm{O}$ site [37]. Their calculations thus suggested that only $\mathrm{N}$ is a viable substitutional acceptor in $\mathrm{ZnO}$. Another consequence of their calculations is the formation of complexes between $\mathrm{Zn}_{i}$ and $\mathrm{N}_{\mathrm{O}}$ as a function of growth environment. For example, the formation energy $E_{f}$ of $\left(\mathrm{Zn}_{i}+\mathrm{N}_{\mathrm{O}}\right)$ under O-rich conditions is $6.58 \mathrm{eV}$ but can be as low as $0.8 \mathrm{eV}$ at the $\mathrm{Zn}$-rich limit [37].

Lee et al. [46] also used first principles pseudopotential calculations within the LDA to describe the localized nature of the $\mathrm{Zn} 3 d$ and $\mathrm{O} 2 p$ wave functions to explain compensation mechanisms in $\mathrm{N}$-doped $\mathrm{ZnO}$. The conclusion from Lee's calculations mirrors others $[13,14]$ in that $V_{\mathrm{Zn}}$ is the most stable defect under O-rich conditions from midgap to the CBM. While $V_{\mathrm{Zn}}$ acts as an acceptor, his focus is on the compensating species such as $V_{\mathrm{O}}, \mathrm{Zn}_{i}, \mathrm{Zn}_{\mathrm{O}}$, and the shallow double donor, $\left(\mathrm{N}_{2}\right)_{\mathrm{O}}{ }^{2+}$, as $E_{F}$ changes from the CBM to the VBM. The low formation energies for complexes of those defects with $\mathrm{N}_{\mathrm{O}}$ suggest that $\mathrm{N}$-doping is inefficient under $\mathrm{O}$ rich conditions because the total atomic concentration, $[\mathrm{N}]$, of incorporated N impurities is below $8 \times 10^{12} \mathrm{~cm}^{-3}$ which leads to very low hole densities [46]. In the $\mathrm{Zn}$-rich limit however, since the $E_{f}$ of $\mathrm{N}_{\mathrm{O}}$ decreases significantly, both hole and $\mathrm{N}$ concentrations increase, leading to $[\mathrm{N}] \sim 10^{15}-2 \times$ $10^{17} \mathrm{~cm}^{-3}$ with resultant hole carrier densities that saturate at $\sim 2 \times 10^{15} \mathrm{~cm}^{-3}$. For growth processes using a $\mathrm{N}_{2}$ source in an electron cyclotron resonance, $\mathrm{ECR}$, and plasma, $\mathrm{N}$ solubility is expected to increase under O-rich conditions. However, $\left(\mathrm{N}_{2}\right)_{\mathrm{O}}$ molecules are the dominant compensating species. So even though $[\mathrm{N}]$ increases with this active source, the hole carrier density decreases because of compensation by $\left(\mathrm{N}_{2}\right)_{\mathrm{O}}$ molecules and unintentional $\mathrm{H}$ impurities from $\mathrm{H}_{2} \mathrm{O}$ within the growth system. Lee et al. [46] concludes that for low [N], 
$\mathrm{N}_{\mathrm{O}}$ acceptors are compensated by $V_{\mathrm{O}}$, while for high [N], $\mathrm{N}_{\mathrm{O}}$ acceptors are compensated by $\mathrm{N}_{\mathrm{O}}-\mathrm{Zn}_{\mathrm{O}}$ complexes.

Troubled by acceptor levels for $\mathrm{N}$ in $\mathrm{ZnO}$ generated by DFT calculations within the LDA or generalized gradient approximation (GGA) [37, 46], Lyons et al. [47] performed first principles calculations using hybrid functionals. These calculations lead to a band gap of $\mathrm{ZnO}$ of $3.4 \mathrm{eV}$. They found that $\mathrm{N}_{\mathrm{O}}$ can be stable in either the neutral or -1 charge states, with the acceptor level occurring at $1.3 \mathrm{eV}$ above the VBM [47], as mentioned above. The discrepancy between their calculations and those of Park et al. [37] and Lee et al. [46] in which $\mathrm{N}$ is predicted to be a more shallow acceptor were attributed to the downward shift of the VBM on an absolute energy scale. They verified their calculations for $\mathrm{N}_{\mathrm{O}}$ in $\mathrm{ZnO}$ by repeating them for $\mathrm{N}_{\mathrm{Se}}$ in ZnSe. Their calculations were consistent with experimental findings that the ionization energy for $\mathrm{N}_{\mathrm{Se}}$ is $100 \mathrm{meV}$ [47]. They assigned the difference in ionization energies of the $\mathrm{N}$ acceptors to the band structure of the host as follows. In $\mathrm{ZnO}$, the VBM is derived from the $\mathrm{O} 2 p$ orbitals. In $\mathrm{ZnSe}$, the VBM is derived from the Se $4 p$ orbitals. Since N $2 p$ orbitals are $3 \mathrm{eV}$ lower than Se $4 p$ orbitals in $\mathrm{ZnSe}$, but $\sim 3 \mathrm{eV}$ higher than $\mathrm{O} 2 p$ orbitals in $\mathrm{ZnO}$, it follows that the transfer of an electron from the VBM to the $\mathrm{N}$ acceptor is more energetically favorable in $\mathrm{ZnSe}$, but nearly impossible in $\mathrm{ZnO}$ [47]. Experimental confirmation of $\mathrm{N}$ as a deep acceptor in bulk $\mathrm{ZnO}$ grown in an $\mathrm{NH}_{3}$ ambient was reported by Tarun et al. [55] based on two key observations: (1) an IR absorption peak at $3148 \mathrm{~cm}^{-1}$ attributed to a N-H complex and (2) a broad PL emission centered at $1.7 \mathrm{eV}$, the intensity of which increased with the activated $\mathrm{N}$ concentration. Activation of $\mathrm{N}$ as a deep acceptor was accomplished by annealing in a $0.5 \mathrm{~atm} \mathrm{O}_{2}$ ambient, which dissociated $\mathrm{N}-\mathrm{H}$ pairs to form the isolated $\mathrm{N}_{\mathrm{O}}$. Presence of the broad $1.7 \mathrm{eV}$ emission was claimed to be in agreement with the deep acceptor model [47] for an isolated substitutional $\mathrm{N}$ in $\mathrm{ZnO}$ proposed by Lyons, et al. Nevertheless, numerous publications have reported Nrelated relatively shallow acceptor levels (see Table 2) that are consistent with p-type conduction. As discussed below, these shallow acceptor levels are related to defect complexes involving $\mathrm{N}_{\mathrm{O}}$ and not an isolated $\mathrm{N}$ on the oxygen site.

Minegishi et al. [19] was the first to realize p-type conduction at room temperature in $\mathrm{ZnO}$ films by incorporating $\mathrm{N}$ during chemical vapor deposition (CVD) of $\mathrm{ZnO}$ on (0001) sapphire substrates. Secondary ion mass spectroscopy (SIMS) was used to confirm the presence, but not absolute concentration, of $\mathrm{N}$ in those films given the simultaneous addition of $\mathrm{NH}_{3}$ to the $\mathrm{H}$ carrier gas and a $10 \mathrm{~mol} \%$ mixture of metallic $\mathrm{Zn}$ and $\mathrm{ZnO}$ powder. Their $\mathrm{N}$-doped films exhibited resistivities that ranged from 34 to $175 \Omega-\mathrm{cm}$ with Hall mobilities of $12-30 \mathrm{~cm}^{2} \mathrm{~V}^{-1} \mathrm{~s}^{-1}$ for substrate temperatures of $650-750^{\circ} \mathrm{C}$, respectively. However, there was a very narrow temperature window in which the excess $\mathrm{Zn}$ was able to catalyze $\mathrm{N}$ to combine with $\mathrm{H}$ in the film to form $\mathrm{ZnNH}$, resulting in the activation of the $\mathrm{N}$ acceptor [19]. For the film that did invert to $\mathrm{p}$-type conduction, the acceptor ionization energy was estimated to be $100 \mathrm{meV}$ which is the lowest reported to date (see Table 2) and seems low for the $\mathrm{N}$ incorporation suggested by a hole carrier density of only $1.5 \times 10^{16} \mathrm{~cm}^{-3}$. If one assumes that their estimate of the ionization energy is correct, then one can only conclude that their nitrogen incorporation is quite low.

Probably the results that have stimulated the most renewed interest in $\mathrm{ZnO}$ were those by Look et al. [20]. They were the first to show reproducible $\mathrm{N}$-doped p-type $\mathrm{ZnO}$ grown by $\mathrm{MBE}$ on $\mathrm{Li}$-doped semi-insulating $\mathrm{ZnO}$ substrates by adding $\mathrm{N}_{2}$ to the $\mathrm{O}_{2}$ gas flow in the RF plasma source. SIMS measurements revealed the nitrogen concentration, $[\mathrm{N}]$, at the surface of $\sim 9 \times 10^{18} \mathrm{~cm}^{-3}$ with a corresponding hole concentration of $9 \times 10^{16} \mathrm{~cm}^{-3}$, which implied a $1 \%$ activation of the $\mathrm{N}$ acceptor. Van der Pauw Hall measurements also gave average values of $\rho=40 \Omega$-cm and $\mu_{p}=2 \mathrm{~cm}^{2} \mathrm{~V}^{-1} \mathrm{~s}^{-1}$. Their low temperature ( $4 \mathrm{~K}) \mathrm{PL}$ reported the acceptor-bound exciton $\left(\mathrm{A}^{0} \mathrm{X}\right)$ associated with $\mathrm{N}_{\mathrm{O}}$ at $3.315 \mathrm{eV}$, and the acceptor ionization energy was estimated to be $0.17-0.20 \mathrm{eV}$ [20]. Their hole concentrations were consistent with the estimated ionization energy and were in agreement with those predicted by the nondegenerate, single-donor/single-acceptor model [56]. SIMS, Hall, and PL measurements were also consistent with those for p-type GaN and other p-type II-VI compounds.

Zeng et al. [25] grew $\mathrm{N}$-doped $\mathrm{ZnO}$ thin films on a-plane (11-20) sapphire substrates by plasma-assisted low-pressure (5 Pa) MOVPE. An NO plasma was used as the source for both the oxygen source and the $\mathrm{N}$ dopant source. Growth temperatures ranged from 250 to $500^{\circ} \mathrm{C}$ in $50^{\circ} \mathrm{C}$ increments. All films were grown at $450^{\circ} \mathrm{C}$ and below exhibited ptype behavior. Room temperature (RT) van der Pauw Hall characteristics were optimal for a growth temperature of $400^{\circ} \mathrm{C}$. Resistivity was lowest $(1.72 \Omega-\mathrm{cm})$ as was hole mobility $\left(1.59 \mathrm{~cm}^{2} \mathrm{~V}^{-1} \mathrm{~s}^{-1}\right)$. Hole concentrations were also maximized at $2.29 \times 10^{18} \mathrm{~cm}^{-3}$. Scanning electron microscopy (SEM) of surfaces of films grown at $300^{\circ} \mathrm{C}, 400^{\circ} \mathrm{C}$, and $500^{\circ} \mathrm{C}$ supported Zeng et al's [25] assertion that less $\mathrm{N}$ is incorporated at higher temperatures as did the relative intensities from RT photoluminescence. The free electron-to-neutral-acceptor (e, $\mathrm{A}^{0}$ ) transition was most pronounced for their $400^{\circ} \mathrm{C}$ film. From the $\left(\mathrm{e}, \mathrm{A}^{0}\right)$ peak position, the acceptor ionization was estimated to be $180 \mathrm{meV}$. The very impressive aspect of this study was the wide range of temperature and the repetitive consistency with which p-type conductivity was achieved.

As mentioned in the codoped section above, Dutta et al. [26] used a sol gel process to investigate both $\mathrm{N}$-doped and $(\mathrm{Al}, \mathrm{N})$ codoped $\mathrm{ZnO}$. The sol-gel film was spin coated, post-baked, and then heated at $550^{\circ} \mathrm{C}$ in an oxygen ambient for $30 \mathrm{~min}$. The decomposition pathway of the ammonium acetate gave $\mathrm{NO}$ and $\mathrm{NO}_{2}$ to act as the $\mathrm{N}$ source. $\mathrm{X}$-ray diffraction (XRD) patterns of their $\mathrm{ZnO}: \mathrm{N}$ showed (002) as well as (101) plane reflections. However, their N-doped only films showed unstable behavior. Hall measurements fluctuated between $\mathrm{p}$ - and $\mathrm{n}$-type with concentrations and mobilities in the range of $(-) 6.53 \times 10^{13} \mathrm{~cm}^{-3}$ to $(+) 5.95 \times 10^{14} \mathrm{~cm}^{-3}$ and $66.5 \mathrm{~cm}^{2} \mathrm{~V}^{-1} \mathrm{~s}^{-1}$ to $6.4 \mathrm{~cm}^{2} \mathrm{~V}^{-1} \mathrm{~s}^{-1}$. The anomalous Hall behavior is consistent with their low XRD $c$-axis value of $0.5218 \mathrm{~nm}$ suggesting $<0.1$ atomic $\% \mathrm{~N}$ in the film [57].

Myers et al. [30] used PLD and ion implantation of $\mathrm{N}^{+}$ ions at three different fluences $3 \times 10^{14} \mathrm{~cm}^{-2}, 6 \times 10^{14} \mathrm{~cm}^{-2}$, 
and $1.2 \times 10^{15} \mathrm{~cm}^{-2}$ and dynamic annealing at 300, 380, and $460^{\circ} \mathrm{C}$ for each fluence. Simulations predicted maximum implanted concentration of $8 \times 10^{19} \mathrm{~cm}^{-3}$ at a depth of $120 \mathrm{~nm}$ for the highest implant fluence of $1.2 \times 10^{15} \mathrm{~cm}^{-3}$. All samples implanted at 300 and $380^{\circ} \mathrm{C}$ were n-type except for the lowest fluence at $380^{\circ} \mathrm{C}$. However, samples for all fluences implanted at $460^{\circ} \mathrm{C}$ exhibited p-type conductivity and their resistivity decreased from $71 \Omega-\mathrm{cm} \rightarrow 50 \Omega-\mathrm{cm} \rightarrow$ $18 \Omega-\mathrm{cm}$ as fluence increased. As resistivity decreased, hole carrier concentration increased from $2.4 \times 10^{16} \mathrm{~cm}^{-3} \rightarrow 1.9 \times$ $10^{17} \mathrm{~cm}^{-3} \rightarrow 2.4 \times 10^{17} \mathrm{~cm}^{-3}$. Hall mobilities ranged from 0.7 to $3.7 \mathrm{~cm}^{2} \mathrm{~V}^{-1} \mathrm{~s}^{-1}$. Transmission electron microscopy (TEM) of films that exhibited n-type conductivity confirmed that low temperature implantation created defect clusters and damage instead of substitutional incorporation of dopants. Conversely, stacking faults were a characteristic of all the p-type samples. Based on their simulations, at an implant temperature of $460^{\circ} \mathrm{C}$, they were able to activate $0.3 \%$ of the implanted $\mathrm{N}^{+}$ions.

Ion implantation provides a means of incorporating controllable amounts of dopant into the $\mathrm{ZnO}$ matrix to help elucidate the relevant mechanisms for p-type conduction. Recently, Stehr et al. [49] used this technique to maximize the formation of certain intrinsic defects by coimplanting $\mathrm{N}^{+}$ with $\mathrm{O}^{+}$or $\mathrm{Zn}^{+}$into bulk $\mathrm{ZnO}$ crystals at $300 \mathrm{~K}$. Following implantation, crystals were annealed in either $\mathrm{N}_{2}$ or $\mathrm{O}_{2}$ at $800^{\circ} \mathrm{C}$ for $2 \mathrm{~min}$. Raman spectra of their crystals contained local vibration modes at $277 \mathrm{~cm}^{-1}, 511 \mathrm{~cm}^{-1}$, and $581 \mathrm{~cm}^{-1}$ which have been previously associated with $\mathrm{N}[58,59]$. The PL spectra of their codoped ion implanted samples revealed three major points. First, the $\mathrm{I}_{4}$ line normally present for undoped $\mathrm{ZnO}$ disappeared after codoping implantation with either $\mathrm{N}$ and $\mathrm{O}$ or $\mathrm{N}$ and $\mathrm{Zn}$. They attributed this to consumption of $\mathrm{H}$ by the formation of complexes with $\mathrm{N}$ in the implanted ZnO. Secondly, PL lines at 3.3128 and $3.2405 \mathrm{eV}$ appeared after implantation. These lines have been assigned to the recombination of excitons bound to a neutral acceptor $\left(\mathrm{A}^{0} \mathrm{X}\right)[20,60]$ and also to free electron to acceptor (FA) transitions [61]. The presence of these PL signatures is consistent with the observations of Look et al. [20]; however, the interpretation of the origin, single $\mathrm{N}_{\mathrm{O}}$ versus an acceptor complex, remains quite controversial. Stehr et al. [49] suggested that this defect is most likely a complex that contains a $\mathrm{N}$ atom because the acceptor energies estimated by Stehr et al. [49] and Look et al. [20] are too small to be substitutional nitrogen on the oxygen site. Thirdly, the intensity of the $\mathrm{A}^{0} \mathrm{X}$ emission for $\mathrm{ZnO}$ samples implanted with $\mathrm{N}$ and $\mathrm{Zn}$ was highest for those annealed in $\mathrm{O}_{2}$ and lowest for those annealed in $\mathrm{N}_{2}$. This annealing behavior suggested that while defect formation was favored under $\mathrm{Zn}$ rich conditions, it was also suppressed by oxygen deficiency [49]. For those samples coimplanted with $\mathrm{N}$ and O, a PL band at $3.23 \mathrm{eV}$ accompanied by an LO-assisted transition was assigned as the donor to acceptor pair (DAP) transitions related to a nitrogen acceptor. Assuming a shallow $(52 \mathrm{meV})$ donor is participating in the DAP transitions, the ionization energy $(160 \mathrm{meV})$ suggests this $\mathrm{N}$-related acceptor is also a complex defect. This binding energy is similar to the energy level of a $\mathrm{N}_{\mathrm{Zn}}-2 \mathrm{~V}_{\mathrm{Zn}}$ complex seen in $\mathrm{Zn}$-deficient conditions [49]. Their optically detected magnetic resonance (ODMR) measurements of samples with coimplantation of $\mathrm{N}$ and $\mathrm{O}$ gave insight about another defect. When studied in the visible spectrum, the ODMR signal for samples annealed in $\mathrm{N}_{2}$ was broad and its intensity was diminished relative to those annealed in $\mathrm{O}_{2}$ or the reference $\mathrm{ZnO}$ crystal. The angular dependence of that broad signal suggested the defect was related to the deep donor, $\mathrm{N}_{\mathrm{Zn}}$, which has favorable formation energy under oxygen-rich conditions [62]. However, when studied under near-IR emission, that same deep donor signal was detected but was paired with an additional defect, a deep acceptor $\mathrm{N}_{\mathrm{O}}$. These same defects were not present for samples coimplanted with $\mathrm{N}$ and $\mathrm{Zn}$. These ODMR signals present the first evidence for the $\mathrm{N}$ antisite that Liu et al. [63] suggested and is fundamental to the work done by Reynolds et al. [36].

Sui et al. [33] codoped $\mathrm{ZnO}$ films with Group VA elements $\mathrm{P}$ and $\mathrm{N}$ by magnetron sputtering and post-growth annealing to generate p-type material. Their source material was a mixture of argon and nitrogen used to (RF) sputter $\mathrm{ZnO}$ and 2 wt. $\% \mathrm{P}_{2} \mathrm{O}_{5}$ powders onto quartz substrates at $500^{\circ} \mathrm{C}$. Post-growth annealing was performed in a tube furnace for $30 \mathrm{~min}$ at $800^{\circ} \mathrm{C}$. Their RT resistivity was found to be $3.98 \Omega-\mathrm{cm}$ with a Hall mobility of $1.35 \mathrm{~cm}^{2} \mathrm{~V}^{-1} \mathrm{~s}^{-1}$ and a hole concentration of $1.16 \times 10^{18} \mathrm{~cm}^{-3}$. The electrical properties for $\mathrm{ZnO}:(\mathrm{P}, \mathrm{N})$ were greatly improved, $10 \mathrm{x}$ and $100 \mathrm{x}$, over those samples doped with $\mathrm{P}$ or $\mathrm{N}$ alone, respectively. The $\mathrm{ZnO}: \mathrm{P}$ and $\mathrm{ZnO}: \mathrm{N}$ resistivities were an order of magnitude lower and their carrier concentrations were $2.3 \times 10^{17} \mathrm{~cm}^{-3}$ and $1.18 \times 10^{16} \mathrm{~cm}^{-3}$, respectively. The higher mobility $\left(10.8 \mathrm{~cm}^{2} \mathrm{~V}^{-1} \mathrm{~s}^{-1}\right)$ for the $\mathrm{ZnO}: \mathrm{N}$ sample is consistent with the lower carrier concentration. All samples showed p-type conductivity. Sui et al. [33] also presented $I-V$ characteristics for their homojunction of undoped n-type $\mathrm{ZnO}$ and p-type $\mathrm{ZnO}$, which used $\mathrm{Ni} / \mathrm{Au}$ for the p-contacts and In for the $\mathrm{n}$-contacts. The rectifying behavior is clearly present albeit the current is low $(-2 \mu \mathrm{A}<I<2 \mu \mathrm{A})$ for a drive voltage from $-15 \mathrm{~V}<V<15 \mathrm{~V}$. Using SIMS, they compared the $\mathrm{N}$ incorporation in a film that was codoped with $\mathrm{N}$ and $\mathrm{P}$ with one doped with $\mathrm{N}$ alone. While no absolute concentrations were given, the relative incorporation of $\mathrm{N}$ is an order of magnitude higher in the $(\mathrm{P}, \mathrm{N})$ codoped sample. Their $\mathrm{P}_{2 p}$ XPS spectra gave a binding energy of between 133.3 and $133.8 \mathrm{meV}$ for the $\mathrm{ZnO}:(\mathrm{P}, \mathrm{N})$ sample indicating that $\mathrm{P}$ did not substitute for $\mathrm{O}$ but rather occupied a $\mathrm{Zn}$ site. The $\mathrm{N}_{1 s} \mathrm{XPS}$ spectrum showed two peaks, one at $397.6 \mathrm{eV}$ and another at $402.5 \mathrm{eV}$. The lower peak indicates that the $\mathrm{N}$ atom substitutes for the $\mathrm{O}$ atom to form the $\mathrm{N}_{\mathrm{O}}$ acceptor in the $\mathrm{ZnO}$ : $(\mathrm{P}$, $\mathrm{N})$ sample. The higher, less intense peak is attributed to $\left(\mathrm{N}_{2}\right)_{\mathrm{O}}$ which is considered a double donor. Their PL data over the temperature range from 83 to $300 \mathrm{~K}$ showed the FA transition at $3.310 \mathrm{eV}$, a DAP transition at $3.241 \mathrm{eV}$, and its longitudinal optical (LO) phonon replica separated by $72 \mathrm{meV}$ at $3.168 \mathrm{eV}$. Their FA peak exhibits the characteristic redshift while the DAP emission continually shows a blueshift as shallow donors are ionized with increasing temperature as the ionized free electrons in the conduction band prefer to recombine with acceptors to form FA [64]. The formation 
mechanism for the $\mathrm{p}$-type $\mathrm{ZnO}:(\mathrm{P}, \mathrm{N})$ is that $\mathrm{P}$ occupies the $\mathrm{Zn}$ site, $\mathrm{P}_{\mathrm{Zn}}$, and $\mathrm{N}$ occupies the $\mathrm{O}$ site $\left(\mathrm{N}_{\mathrm{O}}\right)$ forming a neutral passive $\mathrm{P}_{\mathrm{Zn}}-3 \mathrm{~N}_{\mathrm{O}}$ complex which may form an additional fully occupied impurity band above the VBM. When additional $\mathrm{N}$ is introduced into the system with the $\mathrm{P}_{\mathrm{Zn}}-3 \mathrm{~N}_{\mathrm{O}}$ defect complex, the $\mathrm{N}$ and $\mathrm{P}_{\mathrm{Zn}}-3 \mathrm{~N}_{\mathrm{O}}$ combine to form more energetically favored $\mathrm{P}_{\mathrm{Zn}}-4 \mathrm{~N}_{\mathrm{O}}$ complex acceptors. As a consequence, the electrons transit from the impurity band which lowers the ionization energy, and the p-conduction arises from the $\mathrm{P}_{\mathrm{Zn}^{-}}$ $4 \mathrm{~N}_{\mathrm{O}}$ acceptor complex.

The fact that low experimental acceptor ionization energies for Group VA on an oxygen site have been reported suggests that the origin of $\mathrm{p}$-conductivity in $\mathrm{ZnO}$ is most likely not associated with a single VA substitution on an $\mathrm{O}$ site but must be explained by a more complex and multistep approach. Catlow el al. [65] showed that the fundamental reactions necessary to generate defect species $V_{\mathrm{Zn}}{ }^{-2}, V_{\mathrm{O}}{ }^{+2}, \mathrm{O}_{i}^{-2}, \mathrm{Zn}_{i}{ }^{+2}$, and hole formation require energy while reactions for electron generation and $\mathrm{ZnO}(\mathrm{s})$ formation release energy. So, from a thermodynamic perspective, except under conditions of very high chemical potential, defect compensation is more favorable than hole compensation under equilibrium conditions [65]. However, experimental data suggests that by controlling the growth conditions, defect solubility may be coerced such that donor defect species provide metastable routes to acceptor complexes capable of providing mobile holes in $\mathrm{ZnO}$. Liu et al. [63] suggested that since the absorption energy for $\mathrm{N}_{\mathrm{Zn}}$ is $0.08 \mathrm{eV}$ for the hexagonal close packed structure of the Zn-polar surface, it may be possible for $\mathrm{N}$ to absorb to bulk $\mathrm{Zn}$ sites, resulting in $\mathrm{N}_{\mathrm{Zn}}$ bonded to 3 neighboring $\mathrm{O}$ atoms on the zinc-polar oxygen surface. This suggestion is consistent with the formation energies for $V_{\mathrm{Zn}}{ }^{-2}$ under O-rich conditions as shown in Figure 2. But it necessitates the amphoteric behavior of $\mathrm{N}$ in $\mathrm{ZnO}$ under O-rich conditions leading to the formation of $\mathrm{N}_{\mathrm{Zn}}$ antisites.

Reynolds et al. [36] suggested that if the MOVPE growth conditions were alternated from O-rich to Zn-rich, it would be energetically less favorable for $\mathrm{O}$ to bond to the $\mathrm{N}_{\mathrm{Zn}}$ than to form an $V_{\mathrm{O}}{ }^{0}$ since its $E_{f}$ is $\sim 0.1 \mathrm{eV}$ across the entire Fermi level range. The result would be the formation of $\mathrm{N}_{\mathrm{Zn}}-V_{\mathrm{O}}$ which according to Liu et al. [63] are metastable double donors. By repeating the O-rich then $\mathrm{Zn}$-rich growth environment in a cyclic manner, $\mathrm{ZnO}$ films containing high concentrations of $\mathrm{N}_{\mathrm{Zn}}-V_{\mathrm{O}}$ can be achieved. During the cool down after growth, the metastable nature of these donors requires an input of energy via an in situ anneal that must satisfy two criteria. The first is that the ambient gas must create sufficient overpressure to minimize nitrogen from leaving the film. Secondly, the thermal energy must be sufficient to promote the $\mathrm{N}$ on the $\mathrm{Zn}$ site to hop to the adjacent vacant $\mathrm{O}$ site, the result of which is to convert the double donor complex, $\mathrm{N}_{\mathrm{Zn}}-V_{\mathrm{O}}$, to a double acceptor complex, $V_{\mathrm{Zn}^{-}}$ $\mathrm{N}_{\mathrm{O}}$. The first condition can be met with an $450^{\circ} \mathrm{C}$ in situ anneal in $\mathrm{N}_{2} \mathrm{O}$ since the change in the Gibbs free energy, $\Delta \mathrm{G}_{f}$, favors formation of $\mathrm{NO}$ and $\mathrm{N}$ rather than $\mathrm{N}_{2}$. Since the thermal energy will also break bonds between $\mathrm{H}$ and native defects, $\mathrm{H}^{+}$will diffuse through the lattice to compensate

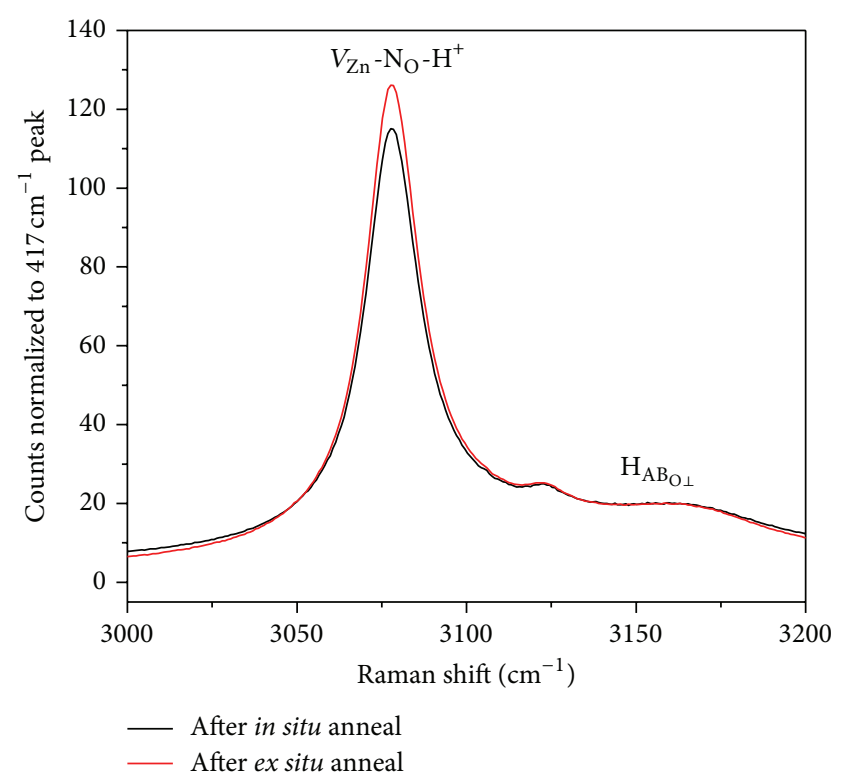

FIgURE 4: Raman spectra of a N-doped $\mathrm{ZnO}$ film exhibits the $V_{\mathrm{Zn}}-\mathrm{N}_{\mathrm{O}}-\mathrm{H}^{+}$single acceptor complex at a vibration frequency of $3078 \mathrm{~cm}^{-1}$ after the in situ anneal (black) as well as after an ex situ $800^{\circ} \mathrm{C} \mathrm{O}_{2}$ anneal.

other defects. Reynolds et al. [36] used Raman spectroscopy to reveal a local vibration mode consistent with a $V_{\mathrm{Zn}}-\mathrm{N}_{\mathrm{O}^{-}}$ $\mathrm{H}^{+}$single acceptor complex at a vibration frequency of the $3078 \mathrm{~cm}^{-1}$ (see Figure 4) that is present after the in situ anneal. Since $\mathrm{H}^{+}$always acts as a donor and its diffusivity in $\mathrm{ZnO}$ is high, an additional $800^{\circ} \mathrm{C}$ ex situ anneal was necessary to remove excess $\mathrm{H}^{+}$bound to $\mathrm{O}_{i}^{-1(\text { oct) }}$ and $\mathrm{Zn}_{i}{ }^{-1 \text { (oct) }}$ from the film as shown in Figure 5. The duration of the ex situ anneal is critical because the acceptor complex $V_{\mathrm{Zn}}-\mathrm{N}_{\mathrm{O}}-\mathrm{H}^{+}$can be isochronally reduced, depending on the annealing ambient, while defects contributing to n-type conductivity are reduced. This suggests that net doping is determined by the relative rate at which acceptor and donor complexes are reduced. As long as the binding and dissociation energies are higher for the $V_{\mathrm{Zn}}-\mathrm{N}_{\mathrm{O}}-\mathrm{H}^{+}$complex than for other $\mathrm{H}^{+}$-decorated species, (Figure 6) p-type conductivity prevails. Indeed, a $30 \mathrm{~s}, 800^{\circ} \mathrm{C}$ ex situ anneal in $\mathrm{N}_{2}$ has been shown to reduce the compensating species in order to realize significant $\mathrm{p}$ type conductivity, $p \sim 3.4 \times 10^{18} \mathrm{~cm}^{-3}$, at room temperature. Consistent p-type polarity was observed on thirty Hall measurements over a range of currents within the linear regime of the IV curve. Contacts on all samples were placed at the corners; the relevance of this to correct determination of carrier type is discussed later within the context of remaining challenges. More recent preliminary magnetic data [66] show that our samples remain p-type after approximately one year, suggesting that our proposed $V_{\mathrm{Zn}}-\mathrm{N}_{\mathrm{O}}-\mathrm{H}^{+}$complex is stable with time. Contrary to our data, others [67] have reported that p-type behavior in $\mathrm{N}$-doped $\mathrm{ZnO}$ degrades over a period of several months becoming n-type when grown on $c$-plane sapphire. However, when grown on a-plane sapphire, Chen et al. [67] demonstrated p-type conduction 
for more than one year. They attributed this instability for $\mathrm{ZnO}$ on $c$-plane sapphire to disappearance of nitrogen on the oxygen site due to compressive stresses associated with lattice misfit. Low temperature (11.6 K) PL studies of a N-doped film exhibiting RT p-type conductivity, shown in Figure 7, determined that the dominant peak is the neutral donor bound exciton $\left(\mathrm{D}^{0} \mathrm{X}\right)$ transition at $3.361 \mathrm{eV}[68]$ and the FA transition at $3.314 \mathrm{eV}$ [69] that undergoes a continuous redshift with increasing temperature. The acceptor ionization energy assigned (using the method described by Wang and Giles [48]) to the $V_{\mathrm{Zn}}-\mathrm{N}_{\mathrm{O}}-\mathrm{H}^{+}$complex is $134 \mathrm{meV}$, which is sufficiently low to allow appreciable room temperature hole conduction as we reported. The structural quality and $\mathrm{N}$ incorporation in our films can be assessed by X-ray diffraction scans. Figure 8 compares patterns for a N-doped film to a nominally undoped one for $\mathrm{ZnO}$ grown on sapphire. Both the sapphire (0006) and (0002) and (0004) reflections for $\mathrm{ZnO}$ are observed. Furthermore, the $\mathrm{N}$-doped sample also exhibits additional (10-11) and (20-22) reflections. In all samples investigated thus far, the FWHM of the (0002) and (0004) reflections for $\mathrm{N}$-doped material are slightly wider, for example, $13.0 \mathrm{~min}$ versus $11.5 \mathrm{~min}$ for nominally undoped. Using the Scherrer formula for X-ray broadening, we estimate the average crystallite size to be $50.2 \mathrm{~nm}$ for nominally undoped material and $44.5 \mathrm{~nm}$ for $\mathrm{N}$-doped films. On the basis of the d-spacing for the (0004) reflection (see Figure 3.3 in [7]), we conclude that our alternating O-rich to Zn-rich growth scheme enables us to incorporate $\sim 0.3-0.5$ at $\% \mathrm{~N}$ in the films. Many have reported inferior crystalline quality of heavily $\mathrm{N}$-doped films, which has led some to suggest that these films are actually polycrystalline and thus attribute p-type conduction in $\mathrm{ZnO}$ to be associated with grain boundaries [70]. These authors discuss segregation of impurities to grain boundaries and subsequent formation of an interfacial complex under O-rich conditions that behaves as an acceptor. Once again this appears to reinforce the concept that complex formation is required for p-type $\mathrm{ZnO}$ as opposed to simple impurity incorporation.

\section{Summary, Conclusions, and Outlook}

Zinc oxide is a fascinating material with numerous potential applications as we have discussed above. Wang et al. [71] has referred to $\mathrm{ZnO}$ as a unique material that has the "richest family of nanostructures among all materials, both in structure and in properties with novel applications in optoelectronics, sensors, transducers, and biomedical sciences." These nanostructures include nanowires, nanobelts, nanorings, and nanocages, for example, and they have succeeded in fabricating a $\mathrm{ZnO}$ nanowire nanogenerator that is able to convert mechanical energy into electrical energy via piezoelectric to semiconductor coupling [71]. Yang et al. [72] have also described fabrication of $\mathrm{N}$-doped $\mathrm{ZnO}$ nanowire arrays in which a DAP recombination has been observed. Although thin strain-free films of $\mathrm{ZnO}$ can be grown homoepitaxially, physical properties of the films can depend on uniformity of crystal quality and presence of defects over the $\mathrm{ZnO}$ substrate and details of the growth

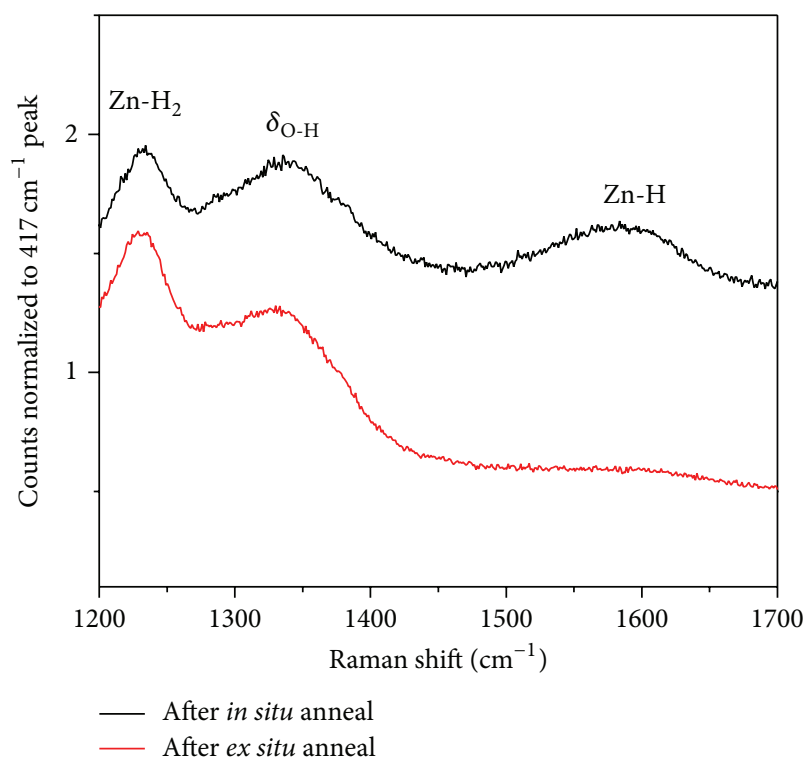

FIgURE 5: Raman spectra of a N-doped $\mathrm{ZnO}$ film show that excess $\mathrm{H}^{+}$bound to the $\mathrm{O}_{i}^{-1(\mathrm{oct})}$ and $\mathrm{Zn}_{i}{ }^{-1 \text { (oct) }}$ present after the in situ anneal (black) is removed from the film after the ex situ $800^{\circ} \mathrm{C} \mathrm{O}_{2}$ anneal (red).

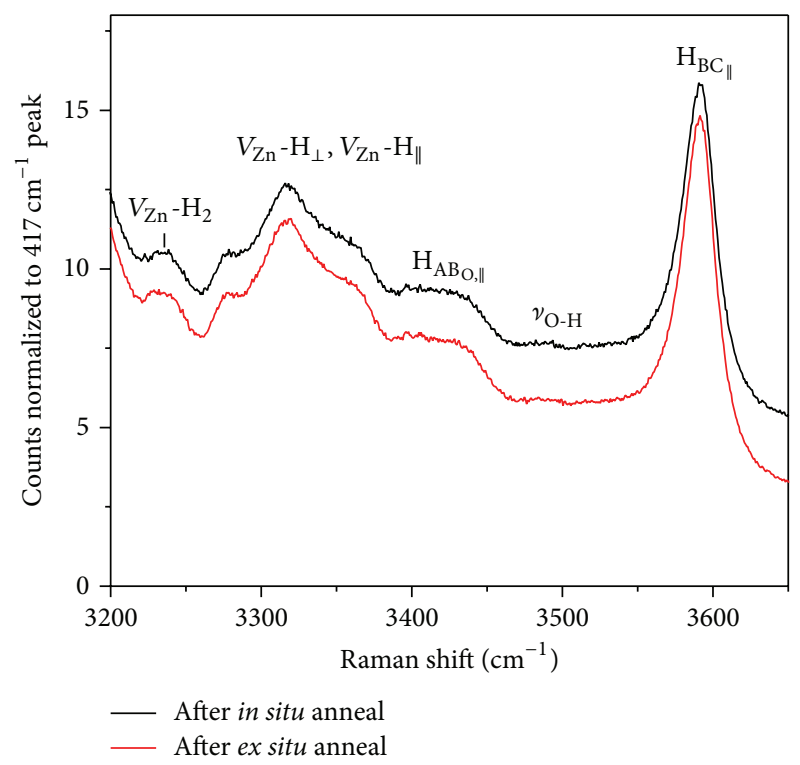

FIGURE 6: Raman spectra of a H-decorated native defects present after the in situ anneal (black) that are reduced after the ex situ $800^{\circ} \mathrm{C}$ $\mathrm{O}_{2}$ anneal (red).

conditions. For example, homoepitaxial MOVPE growth of $\mathrm{ZnO}$ on (11-20) $\mathrm{ZnO}$ substrates revealed the existence of two different morphologies dependent upon the growth ambient [73]. At a growth temperature of $480^{\circ} \mathrm{C}$, a needle microstructure was observed when grown in a $\mathrm{N}$ or $\mathrm{N}_{2} \mathrm{O}+\mathrm{O}_{2}$ environment, whereas a network structure occurred in a $\mathrm{NO}_{2}$ $+\mathrm{O}_{2}$ ambient. Both films coalesced however after $15 \mathrm{~min}$ at $800^{\circ} \mathrm{C}$. More importantly, the nitrogen atomic concentration varied by two orders of magnitude for films grown in the 


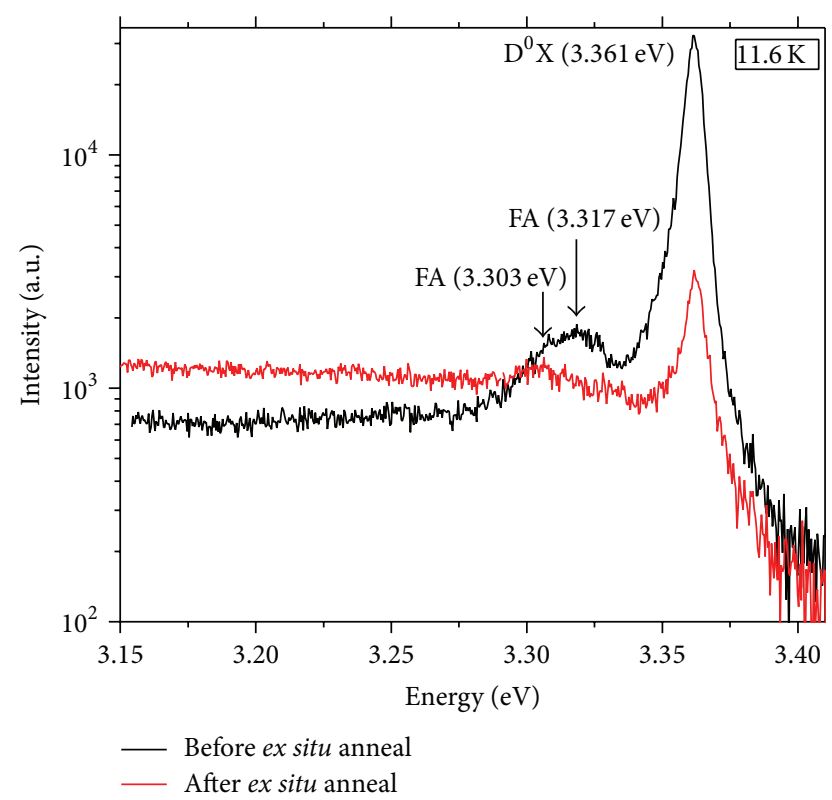

Figure 7: 11.6 K PL spectra of p-type $\mathrm{ZnO}$ before and after the ex situ $800^{\circ} \mathrm{C} \mathrm{O}_{2}$ anneal.

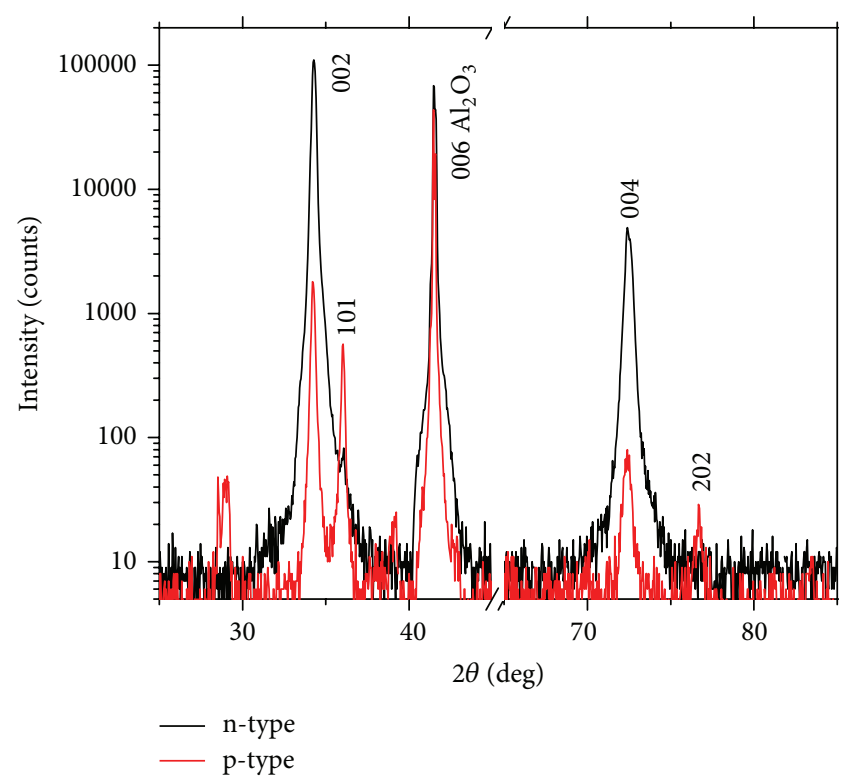

FIGURE 8: Comparison of X-ray spectra for nominally undoped (black) and $\mathrm{N}$-doped (red) $\mathrm{ZnO}$ films grown using an alternating growth scheme.

different ambients $\left(5 \times 10^{17} \mathrm{~cm}^{-3}\right.$ for $\mathrm{N}_{2} \mathrm{O}+\mathrm{O}_{2}$ and $9 \times$ $10^{19} \mathrm{~cm}^{-3}$ for $\mathrm{NO}_{2}+\mathrm{O}_{2}$ ). Using the concept of domain matching epitaxy $[1,2], \mathrm{ZnO}$ thin films are also grown heteroepitaxially across the misfit scale on nonnative substrates such as sapphire and $\mathrm{Si}$ with misfits up to $18 \%$. It is the latter that is particularly exciting as this would enable integration of electronics and optoelectronics on a substrate for multiple functionality. As discussed above, the dominant drawback of $\mathrm{ZnO}$ as an optoelectronic material has been the lack of stable and reproducible p-type conduction at room temperature. To achieve this, one must have sufficient incorporation of the impurity species of interest with relatively shallow ionization energies without significant compensation by unintentional impurities and/or native defects. Satisfying both of these criteria is challenging.

As discussed above, there are three primary strategies that have been investigated to generate appreciable hole conductivity in $\mathrm{ZnO}$ at room temperature: substitution of Group IA impurities on the $\mathrm{Zn}$ sublattice, codoping of donors and acceptors, and substitution of Group VA impurities on the O sublattice. Recent room temperature Hall measurements are summarized in Table 1. On the basis of our analysis above regarding these data, we believe that we are able to assess the likelihood of success for functional devices utilizing each of these approaches, which enables us to postulate several conclusions that have significant impact on the promising outlook for zinc oxide.

With regard to Group IA impurities on a zinc site, the relatively low hole concentrations suggest that $\mathrm{Li}$ and $\mathrm{Na}$ are not optimum dopants in $\mathrm{ZnO}$ in spite of their relatively low ionization energies. The best that has been reported for $\mathrm{Na}$ doped $\mathrm{ZnO}$ is $2.1 \times 10^{17} \mathrm{~cm}^{-3}$ after $254 \mathrm{~nm}$ UV illumination [29]. Such a low doping level is marginal at best for fabricating efficient lasers and/or LEDs. Similarly, codoping of donors and acceptors has resulted in only slightly higher hole concentrations in the low- to mid- $10^{17} \mathrm{~cm}^{-3}$ range $[21,24,26,35]$, and it was necessary to incorporate post-growth annealing in the $(\mathrm{Al}, \mathrm{N})$ codoped films. The latter especially suggests to us that the observed p-type conductivity may be related more to formation of complexes, as discussed above for $\mathrm{N}$ doping of $\mathrm{ZnO}$, during an anneal than codoping per se. In spite of DFT calculations [40] that imply Ga and N codoping should be more effective for p-type behavior than $\mathrm{Al}$ and $\mathrm{N}$ codoping, a comparison of the experimental data in Table 1 reveals no difference between the two. This certainly suggests that a complete understanding of donor/acceptor codoping has thus far not been achieved.

On the basis of analysis above of recent data, it appears in general that Group VA impurities on the oxygen site and more specifically complexes involving nitrogen on an oxygen site, $\mathrm{N}_{\mathrm{O}}$, are the most likely to yield significant $\mathrm{p}$ type conduction. While $\mathrm{Sb}$-doped $\mathrm{ZnO}$ has resulted in an appreciable hole concentration of $1.7 \times 10^{18} \mathrm{~cm}^{-3}$ after an $800^{\circ} \mathrm{C}$ post-growth in situ anneal and the hole concentration increased with the Sb effusion cell temperature [45], Friedrich et al. [51] recently reported that increased $\mathrm{Sb}$ concentrations resulted in Sb-O phase separation while Liu et al. [52] found that lower doping level concentrations lead to donor behavior. This suggests then that a fundamental doping phase space exists for $\mathrm{Sb}$-doped $\mathrm{ZnO}$, which can be deleterious to electronic and photonic devices.

Our view then is that $\mathrm{N}$-doped $\mathrm{ZnO}$ holds the most promise for stable and reproducible p-type behavior. However, as we have described, it cannot be a sole substitutional nitrogen on an oxygen site as the predicted ionization energies are greater than $0.3 \mathrm{eV}$, suggesting $\mathrm{N}_{\mathrm{O}}$ is a deep acceptor without appreciable p-type behavior at $300 \mathrm{~K}$. We thus conclude that $\mathrm{p}$-type conductivity in $\mathrm{N}$-doped $\mathrm{ZnO}$ involves 
formation of complexes that are shallow acceptors with ionization energies that are consistent with those reported in Table 2. It was Liu et al. [63] who used density functional theory and first suggested evolution of a shallow acceptor from a $\mathrm{N}_{\mathrm{Zn}}-V_{\mathrm{O}}$ double donor to a $\mathrm{N}_{\mathrm{O}}-V_{\mathrm{Zn}}$ double acceptor. They based their analysis on the surface reaction pathways for $\mathrm{N}$-doped $\mathrm{ZnO}$. The initial step however was contrary to the statement by Park et al. [37] that nitrogen antisites, that is, $\mathrm{N}_{\mathrm{Zn}}$, do not exist in $\mathrm{ZnO}$. But, the recent experimental results by Reynolds et al. [36] imply that formation of the initial double donor complex in an oxygen rich environment is crucial and thus support the pathway suggested by Liu et al. [63] with the caveat related to the significance of hydrogen. The significance of hydrogen in $\mathrm{ZnO}$ has been well documented by Van de Walle $[42,43]$. Reynolds et al. [36] have recently shown that p-type conduction in $\mathrm{ZnO}$ thin films grown by MOVPE is associated with a three-step process in which one employs an alternating $\mathrm{Zn}$-rich and Orich growth environment to incorporate sufficient nitrogen as a metastable double donor, $\mathrm{N}_{\mathrm{Zn}}-V_{\mathrm{O}}$, on the zinc site, an in situ anneal that supplies sufficient activation energy for the nitrogen to hop to the adjacent oxygen site to form the shallow acceptor complex, $V_{\mathrm{Zn}}-\mathrm{N}_{\mathrm{O}}-\mathrm{H}^{+}$, and lastly, an ex situ anneal to eliminate hydrogen from native defects without removing the acceptor complex. Basically then, one can view formation of p-type conduction during the ex situ anneal as a competition between removing $\mathrm{H}$-decorated native defects without significant reduction of the $V_{\mathrm{Zn}}-\mathrm{N}_{\mathrm{O}}-\mathrm{H}^{+}$acceptor complex, having a resultant ionization energy of $\sim 134 \mathrm{meV}$. Raman spectroscopy was used to follow the reaction pathways under different growth and annealing conditions that enabled the authors to identify [36] the specific complexes involved, which are consistent with the model [63] suggested by Liu, et al. However, there are competing models $[74,75]$ for hole conduction, which our existing data cannot definitively exclude. These models are based on $\mathrm{N}_{O}$ pairs complexed with a hydrogen atom [74] and $\mathrm{N}_{2}$ on a $\mathrm{Zn}$ site [75]. The latter in particular is intriguing considering that the deduced acceptor ionization energy of $165 \mathrm{meV}$ is reasonably close to that which we have estimated. Both Liu et al. [63] and Boonchun and Lambrecht [75] are in agreement that growth on the $\mathrm{Zn}$ polar surface is critical for sufficient nitrogen incorporation. Additional EPR and Raman data may help to elucidate the nature of the relevant complexes. It seems clear to us that routine observations of p-type $\mathrm{N}$-doped $\mathrm{ZnO}$ is based on a complete understanding of the fundamental mechanisms involved and general acceptance of the applicable model.

One might ask what the outstanding challenges that remain for p-type behavior in zinc oxide are. The dominant issue that remains is demonstration of the stability and reproducibility of p-type $\mathrm{ZnO}$, which can only be accomplished by additional growth under the conditions described and subsequent Hall and Raman measurements over time. There must be a critical assessment of the Hall measurements and associated data. It is generally recognized that it is difficult to make contacts to $\mathrm{ZnO}$, and, hence, one might question interpretation of Hall results. One of the issues that have been discussed with regard to interpretation of Hall measurements for polarity is sample uniformity and placement of contacts.
Ohgaki et al. [76] showed that false positive Hall coefficients can be observed on n-type $\mathrm{ZnO}$ crystals and attributed this behavior to sample inhomogeneity. A subsequent analysis by Bierwagen et al. [77] of various sample nonuniformities and contact placement supported the results in [76]. In particular, they showed that an incorrect polarity type can be deduced in the presence of a nonuniform carrier concentration when contacts are placed in the interior of the sample. Most importantly though, they demonstrated that the correct carrier type can be inferred if contacts are placed at sample corners even if inhomogeneities exist. Recently, Macaluso et al. [78] have also questioned assignment of carrier type in not-intentionally doped $\mathrm{ZnO}$ grown on an $\mathrm{InP}$ substrate based on conflicting results from Hall data and photocurrent and $\mathrm{C}-\mathrm{V}$ measurements. While their Hall measurements suggested conversion from n-type to p-type material after a post-growth anneal, the latter two techniques indicated that the material remained n-type. Thus, they attributed the anomalous Hall results to a highly conducting p-type layer at the $\mathrm{ZnO} / \mathrm{InP}$ interface formed during a post-growth $600^{\circ} \mathrm{C}$ anneal. This may not be surprising if the defect structure in the $\mathrm{ZnO}$ film allowed $\mathrm{P}$ outdiffusion during the anneal, which would render the interfacial region to be p-type. Lastly, heteroepitaxial growth of $\mathrm{ZnO}$ on various substrates and orientations across the misfit scale may influence the incorporation of dopants as observed in the InP-based system [79].

In summary, recent results described herein strongly suggest that p-type conduction in zinc oxide is feasible based on nitrogen doping on the oxygen sublattice. An understanding of the reaction pathways and specific model to explain the acceptor level is the key to stable and reproducible p-type $\mathrm{ZnO}$. This indeed implies a promising future for zinc oxide based thin film and nanostructured electronic and photonic devices.

\section{Conflict of Interests}

The authors declare that there is no conflict of interests regarding the publication of this paper.

\section{References}

[1] J. Narayan and B. C. Larson, "Domain epitaxy: a unified paradigm for thin film growth," Journal of Applied Physics, vol. 93, no. 1, pp. 278-285, 2003.

[2] J. Narayan, "Recent progress in thin film epitaxy across the misfit scale," Acta Materialia, vol. 61, no. 8, pp. 2703-2724, 2013.

[3] V. Avrutin, D. J. Silversmith, and H. Morkoç, "Doping asymmetry problem in $\mathrm{ZnO}$ : current status and outlook," Proceedings of the IEEE, vol. 98, no. 7, pp. 1269-1280, 2010.

[4] D. C. Look and B. Claflin, " $p$-type doping and devices based on ZnO," Physica Status Solidi B, vol. 241, no. 3, pp. 624-630, 2004.

[5] Y. W. Heo, D. P. Norton, L. C. Tien et al., "ZnO nanowire growth and devices," Materials Science and Engineering R, vol. 47, no. 12, pp. 1-47, 2004.

[6] Ü. Özgür, Y. I. Alivov, C. Liu et al., "A comprehensive review of $\mathrm{ZnO}$ materials and devices," Journal of Applied Physics, vol. 98, no. 4, Article ID 041301, 2005. 
[7] C. Jagadish and S. Pearton, Eds., Zinc Oxide Bulk, Thin Films and Nanostructures, Elsevier, New York, NY, USA, 2006.

[8] H. Morkoc and U. Ozgur, Zinc Oxide: Fundamentals, Materials and Device Technology, Wiley-VCH, Weinheim, Germany, 2009.

[9] A. Janotti and C. G. Van de Walle, "Fundamentals of zinc oxide as a semiconductor," Reports on Progress in Physics, vol. 72, no. 12, Article ID 126501, 2009.

[10] Y. Segawa, H. D. Sun, T. Makino, M. Kawasaki, and H. Koinuma, "Exciton related stimulated emission in $\mathrm{ZnO}$-based multipleduantum wells," Physica Status Solidi A, vol. 192, no. 1, pp. 14-20, 2002.

[11] C. H. Chia, T. Makino, K. Tamura et al., "Confinementenhanced biexciton binding energy in $\mathrm{ZnO} / \mathrm{ZnMgO}$ multiple quantum wells," Applied Physics Letters, vol. 82, no. 12, pp. 18481850, 2003.

[12] T. Dietl, H. Ohno, F. Matsukura, J. Cibert, and D. Ferrand, "Zener model description of ferromagnetism in zinc-blende magnetic semiconductors," Science, vol. 287, no. 5455, pp. 10191022, 2000.

[13] A. F. Kohan, G. Ceder, D. Morgan, and C. G. Van de Walle, "First-principles study of native point defects in $\mathrm{ZnO}$," Physical Review B, vol. 61, no. 22, pp. 15019-15027, 2000.

[14] C. G. Van de Walle, "Defect analysis and engineering in $\mathrm{ZnO}$," Physica B, vol. 308-310, pp. 899-903, 2001.

[15] P. Hohenberg and W. Kohn, "Inhomogeneous electron gas," Physical Review, vol. 136, no. 3, pp. B864-B871, 1964.

[16] W. Kohn and L. J. Sham, "Self-consistent equations including exchange and correlation effects," Physical Review, vol. 140, no. 4, pp. A1133-A1138, 1965.

[17] M. Bockstedte, A. Kley, J. Neugebauer, and M. Sheffler, "Density-functional theory calculations for poly-atomic systems: electronic structure, static and elastic properties and ab initio molecular dynamics," Computer Physics Communications, vol. 107, no. 1-3, pp. 187-222, 1997.

[18] J. Neugebauer and C. G. Van de Walle, "Hydrogen in GaN: novel aspects of a common impurity," Physical Review Letters, vol. 75, no. 24, pp. 4452-4455, 1995.

[19] K. Minegishi, Y. Koiwai, Y. Kikuchi, K. Yan, M. Kasuga, and A. Shimizu, "Growth of $p$-type zinc oxide films by chemical vapor deposition," Japanese Journal of Applied Physics, vol. 36, no. 11, Article ID L1453, 1997.

[20] D. C. Look, D. C. Reynolds, C. W. Litton, R. L. Jones, D. B. Eason, and G. Cantwell, "Characterization of homoepitaxial $p$ type $\mathrm{ZnO}$ grown by molecular beam epitaxy," Applied Physics Letters, vol. 81, no. 10, pp. 1830-1832, 2002.

[21] A. V. Singh, R. M. Mehra, A. Wakahara, and A. Yoshida, " $p$ type conduction in codoped $\mathrm{ZnO}$ thin films," Journal of Applied Physics, vol. 93, no. 1, pp. 396-399, 2003.

[22] F. X. Xiu, Z. Yang, L. J. Mandalapu, D. T. Zhao, J. L. Liu, and W. P. Beyermann, "High-mobility Sb-doped p-type $\mathrm{ZnO}$ by molecular-beam epitaxy," Applied Physics Letters, vol. 87, no. 15, Article ID 152101, 2005.

[23] Y. J. Zeng, Z. Z. Ye, W. Z. Xu et al., "Dopant source choice for formation of p-type $\mathrm{ZnO}$ : Li acceptor," Applied Physics Letters, vol. 88, no. 6, Article ID 062107, 2006.

[24] M. Kumar, T.-H. Kim, S.-S. Kim, and B.-T. Lee, "Growth of epitaxial $p$-type $\mathrm{ZnO}$ thin films by codoping of $\mathrm{Ga}$ and $\mathrm{N}$," Applied Physics Letters, vol. 89, no. 11, Article ID 112103, 2006.

[25] Y. J. Zeng, Z. Z. Ye, W. Z. Xu et al., "Study on the Hall-effect and photoluminescence of $\mathrm{N}$-doped $p$-type $\mathrm{ZnO}$ thin films," Materials Letters, vol. 61, no. 1, pp. 41-44, 2007.
[26] M. Dutta, T. Ghosh, and D. Basak, "N doping and Al-N co-doping in sol-gel $\mathrm{ZnO}$ films: studies of their structural, electrical, optical, and photoconductive properties," Journal of Electronic Materials, vol. 38, no. 11, pp. 2335-2342, 2009.

[27] C. O. Kim, D. H. Shin, S. Kim, S.-H. Choi, K. Belay, and R. G. Elliman, "Effect of $(\mathrm{O}, \mathrm{As})$ dual implantation on $p$-type doping of ZnO films," Journal of Applied Physics, vol. 110, no. 10, Article ID 103708, 2011.

[28] G.-T. Du, W. Zhao, G.-G. Wu et al., "Electrically pumped lasing from $\mathrm{p}-\mathrm{ZnO} / \mathrm{n}-\mathrm{GaN}$ heterojunction diodes," Applied Physics Letters, vol. 101, no. 5, Article ID 053503, 2012.

[29] S. S. Lin, "Robust low resistivity $p$-type $\mathrm{ZnO}: \mathrm{Na}$ films after ultraviolet illumination: the elimination of grain boundaries," Applied Physics Letters, vol. 101, no. 12, Article ID 122109, 2012.

[30] M. A. Myers, M. T. Myers, M. J. General, J. H. Lee, L. Shao, and $\mathrm{H}$. Wang, "P-type $\mathrm{ZnO}$ thin films achieved by $\mathrm{N}^{+}$ion implantation through dynamic annealing process," Applied Physics Letters, vol. 101, no. 11, Article ID 112101, 2012.

[31] J. Huang, Z. Li, S. Chu, and J. Liu, "P-type behavior of Sb doped $\mathrm{ZnO}$ from p-n-p memory structures," Applied Physics Letters, vol. 101, no. 23, Article ID 232102, 2012.

[32] Z. Shi, Y. Zhang, B. Wu et al., "Vertical conducting ultraviolet light-emitting diodes based on $\mathrm{p}-\mathrm{ZnO}$ :As/n-GaN/n-SiC heterostructures," Applied Physics Letters, vol. 102, no. 16, Article ID 161101, 2013.

[33] Y. Sui, B. Yao, L. Xiao et al., "Effects of (P, N) dual acceptor doping on band gap and $p$-type conduction behavior of $\mathrm{ZnO}$ films," Journal of Applied Physics, vol. 113, no. 13, Article ID 133101, 2013.

[34] P. Ding, X. H. Pan, Z. Z. Ye et al., "Realization of $p$-type nonpolar a-plane $\mathrm{ZnO}$ films via doping of $\mathrm{Na}$ acceptors," Solid State Communications, vol. 156, pp. 8-11, 2013.

[35] S. Kalyanaraman, R. Thangavel, and R. Vettumperumal, "High mobility formation of $p$-type $\mathrm{Al}$ doped $\mathrm{ZnO}: \mathrm{N}$ films annealed under $\mathrm{NH}_{3}$ ambient," Journal of Physics and Chemistry of Solids, vol. 74, no. 3, pp. 504-508, 2013.

[36] J. G. Reynolds, C. L. Reynolds, A. Mohanta, J. F. Muth, J. E. Rowe, and D. E. Aspnes, "Shallow acceptor complexes in $p$-type ZnO," Applied Physics Letters, vol. 102, no. 15, Article ID 152114, 2013.

[37] C. H. Park, S. B. Zhang, and S. H. Wei, "Origin of p-type doping difficulty in ZnO: the impurity perspective," Physical Review B, vol. 66, Article ID 073202, 2002.

[38] A. Carvalho, A. Alkauskas, A. Pasquarello, A. K. Tagantsev, and N. Setter, "A hybrid density functional study of lithium in $\mathrm{ZnO}$ : stability, ionization levels, and diffusion," Physical Review B, vol. 80, no. 19, Article ID 195205, 2009.

[39] T. Yamamoto and H. Katayama-Yoshida, "Solution using a codoping method to unipolarity for the fabrication of $p$-type ZnO," Japanese Journal of Applied Physics, vol. 38, no. 2, pp. L166-L169, 1999.

[40] X. M. Duan, C. Stampfl, M. M. M. Bilek, and D. R. McKenzie, "Codoping of aluminum and gallium with nitrogen in $\mathrm{ZnO}$ : a comparative first-principles investigation," Physical Review B, vol. 79, no. 23, Article ID 235208, 2009.

[41] X. M. Duan, C. Stampfl, M. M. M. Bilek, D. R. McKenzie, and S.-H. Wei, "Design of shallow acceptors in $\mathrm{ZnO}$ through early transition metals codoped with $\mathrm{N}$ acceptors," Physical Review B, vol. 83, no. 8, Article ID 085202, 2011.

[42] C. G. Van de Walle, "Hydrogen as a cause of doping in $\mathrm{ZnO}$," Physical Review Letter, vol. 85, article 1012, 2000. 
[43] C. G. Van de Walle and A. Janotti, "Hydrogen in oxides and nitrides: unexpected physics and impact on devices," IOP Conference Series: Materials Science and Engineering, vol. 15, Article ID 012001, 2010.

[44] S.-H. Park, T. Minegishi, D.-C. Oh et al., " $p$-type conductivity of heteroepitaxially grown $\mathrm{ZnO}$ films by $\mathrm{N}$ and Te codoping and thermal annealing," Journal of Crystal Growth, vol. 363, pp. 190194, 2013.

[45] D. C. Look and B. Claflin, "High-quality melt-grown $\mathrm{ZnO}$ single crystals," Physica Status Solidi B, vol. 241, no. 3, pp. 624-630, 2004.

[46] E.-C. Lee, Y.-S. Kim, Y.-G. Jin, and K. J. Chang, "Compensation mechanism for $\mathrm{N}$ acceptors in ZnO," Physical Review B, vol. 64, no. 8, Article ID 085120, 2001.

[47] J. L. Lyons, A. Janotti, and C. G. Van de Walle, "Why nitrogen cannot lead to $p$-type conductivity in ZnO," Applied Physics Letters, vol. 95, no. 25, Article ID 252105, 2009.

[48] L. Wang and N. C. Giles, "Determination of the ionization energy of nitrogen acceptors in zinc oxide using photoluminescence spectroscopy," Applied Physics Letters, vol. 84, no. 16, pp. 3049-3051, 2004.

[49] J. E. Stehr, X. J. Wang, S. Filippov et al., "Defects in N, O, and $\mathrm{N}, \mathrm{Zn}$ implanted ZnO bulk crystals," Journal of Applied Physics, vol. 113, no. 10, Article ID 103509, 2013.

[50] H. von Wenckstern, G. Benndorf, S. Heitsch et al., "Properties of phosphorus doped ZnO," Applied Physics A, vol. 88, no. 1, pp. 125-128, 2007.

[51] F. Friedrich, I. Sieber, C. Klimm, M. Klaus, C. Genzel, and N. H. Nickel, "Sb-doping of $\mathrm{ZnO}$ : phase segregation and its impact on p-type doping," Applied Physics Letters, vol. 98, no. 13, Article ID 131902, 2011.

[52] H. Y. Liu, N. Izyumskaya, V. Avrutin et al., "Donor behavior of $\mathrm{Sb}$ in ZnO," Journal of Applied Physics, vol. 112, no. 3, Article ID 033706, 2012.

[53] A. B. Yankovich, B. Puchala, F. Wang et al., "Stable $p$-type conduction from $\mathrm{Sb}$-decorated head-to-head basal plane inversion domain boundaries in $\mathrm{ZnO}$ nanowires," Nano Letters, vol. 12, no. 3, pp. 1311-1316, 2012.

[54] S. G. Louie, S. Froyen, and M. L. Cohen, "Nonlinear ionic pseudopotentials in spin-density-functional calculations," Physical Review B, vol. 26, no. 4, pp. 1738-1742, 1982.

[55] M. C. Tarun, M. Z. Iqbal, and M. D. McCluskey, "Nitrogen is a deep acceptor in ZnO," AIP Advances, vol. 1, no. 2, Article ID 022105, 2011.

[56] D. C. Look, Electrical Characterization of GaAs Materials and Devices, John Wiley \& Sons, New York, NY, USA, 1989.

[57] T. J. Coutts, X. Li, T. M. Barnes et al., "Chapter 3-synthesis and characterization of nitrogen-doped $\mathrm{ZnO}$ films grown by MOCVD," in Zinc Oxide Bulk, Thin Films and Nanostructures, C. Jagadish and S. Pearton, Eds., pp. 43-83, Elsevier, New York, NY, USA.

[58] A. Kaschner, U. Haboeck, M. Strassburg et al., "Nitrogen-related local vibrational modes in ZnO:N," Applied Physics Letters, vol. 80, no. 11, pp. 1909-1911, 2002.

[59] J. B. Wang, H. M. Zhong, Z. F. Li, and W. Lu, "Raman study of $\mathrm{N}^{+}$-implanted ZnO," Applied Physics Letters, vol. 88, no. 10, Article ID 101913, 2006.

[60] M. Schirra, R. Schneider, A. Reiser et al., "Acceptor-related luminescence at $3.314 \mathrm{eV}$ in zinc oxide confined to crystallographic line defects," Physica B, vol. 401-402, pp. 362-365, 2007.

[61] Y. R. Ryu, T. S. Lee, and H. W. White, "Properties of arsenicdoped $p$-type $\mathrm{ZnO}$ grown by hybrid beam deposition," Applied Physics Letters, vol. 83, no. 1, pp. 87-89, 2003.
[62] P. Li, S. Deng, G. Liu, and K. Hou, "Comprehensive investigations on the feasibility of nitrogen as a $p$-type dopant in $\mathrm{ZnO}$," Chem Phys. Lett, vol. 543, pp. 92-95, 2012.

[63] L. Liu, J. Xu, D. Wang et al., " $p$-Type conductivity in N-doped $\mathrm{ZnO}$ : the role of the $\mathrm{N}_{\mathrm{Zn}}-\mathrm{V}_{O}$ complex," Physical Review Letters, vol. 108, Article ID 215501, 2012.

[64] J. D. Ye, S. L. Gu, F. Li et al., "Correlation between carrier recombination and $p$-type doping in $\mathrm{P}$ monodoped and In-P codoped ZnO epilayers," Applied Physics Letters, vol. 90, no. 15, Article ID 152108, 2007.

[65] C. R. A. Catlow, A. A. Sokol, and A. Walsh, "Microscopic origins of electron and hole stability in $\mathrm{ZnO}$," Chemical Communications, vol. 47, no. 12, pp. 3386-3388, 2011.

[66] C. L. Reynolds Jr. and J. G. Reynolds, "Preliminary magnetization vs applied field indicate that films are p-type," unpublished.

[67] X. Chen, Z. Zhang, B. Yao et al., "Effect of compressive stress on stability of N-doped p-type ZnO," Applied Physics Letters, vol. 99, no. 9, Article ID 091908, 2011.

[68] B. K. Meyer, H. Alves, D. M. Hofmann et al., "Bound exciton and donor-acceptor pair recombinations in ZnO," Physica Status Solidi B, vol. 241, no. 2, pp. 231-260, 2004.

[69] J. W. Sun, Y. M. Lu, Y. C. Liu et al., "Nitrogen-related recombination mechanisms in $p$-type $\mathrm{ZnO}$ films grown by plasma-assisted molecular beam epitaxy," Journal of Applied Physics, vol. 102, no. 4, Article ID 043522, 2007.

[70] J. M. Carlsson, H. S. Domingos, P. D. Bristowe, and B. Hellsing, "An interfacial complex in $\mathrm{ZnO}$ and its influence on charge transport," Physical Review Letters, vol. 91, no. 16, Article ID 165506, 2003.

[71] X. Wang, J. Song, J. Liu, and Z. L. Wang, "Direct-current nanogenerator driven by ultrasonic waves," Science, vol. 316, no. 5821, pp. 102-105, 2007.

[72] B. Yang, P. Feng, A. Kumar, R. S. Katiyar, and M. Achermann, "Structural and optical properties of $\mathrm{N}$-doped $\mathrm{ZnO}$ nanorod arrays," Journal of Physics D, vol. 42, no. 19, Article ID 195402, 2009.

[73] J. M. Pierce, B. T. Adekore, R. F. Davis, and F. A. Stevie, "Homoepitaxial growth of dense $\mathrm{ZnO}$ (0001) and $\mathrm{ZnO}$ (11-20) films via MOVPE on selected $\mathrm{ZnO}$ substrates," Journal of Crystal Growth, vol. 283, no. 1-2, pp. 147-155, 2005.

[74] S. Lautenschlaeger, M. Hofmann, S. Eisermann et al., "A model for acceptor doping in $\mathrm{ZnO}$ based on nitrogen pair formation," Physica Status Solidi B, vol. 248, no. 5, pp. 1217-1221, 2011.

[75] A. Boonchun and W. R. Lambrecht, "Electronic structure of defects and doping in $\mathrm{ZnO}$ : oxygen vacancy and nitrogen doping," Physica Status Solidi B, vol. 250, no. 10, pp. 2091-2101, 2013.

[76] T. Ohgaki, N. Ohashi, S. Sugimura et al., "Positive Hall coefficients obtained from contact misplacement on evident $n$-type ZnO films and crystals," Journal of Materials Research, vol. 23, no. 9, pp. 2293-2295, 2008.

[77] O. Bierwagen, T. Ive, C. G. Van de Walle, and J. S. Speck, "Causes of incorrect carrier-type identification in Van der Pauw-Hall measurements," Applied Physics Letters, vol. 93, no. 24, Article ID 242108, 2008.

[78] R. Macaluso, M. Mosca, C. Cali et al., "Erroneous p-type assignment by Hall effect measurements in annealed $\mathrm{ZnO}$ films grown on InP substrate," Journal of Applied Physics, vol. 113, no. 16, Article ID 164508, 2013.

[79] C. L. Reynolds Jr. and J. A. Grenko, "Crystallographic plane dependent $\mathrm{Fe}$ and Si dopant incorporation and activation in InP," Physica Status Solidi A, vol. 206, no. 4, pp. 691-696, 2009. 

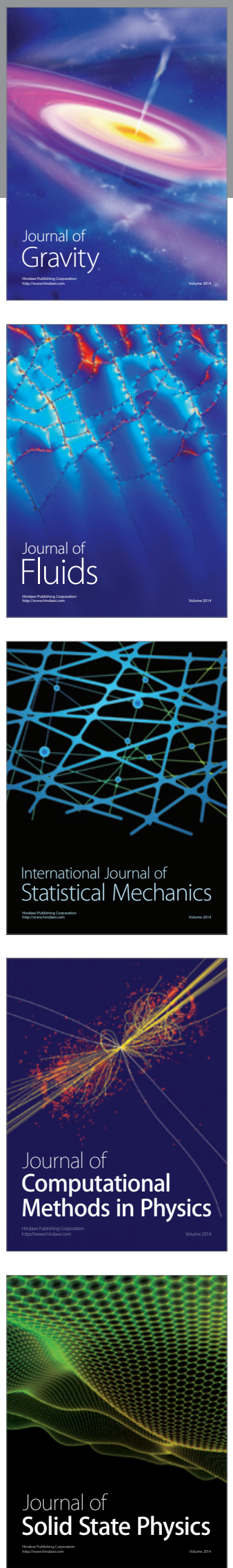

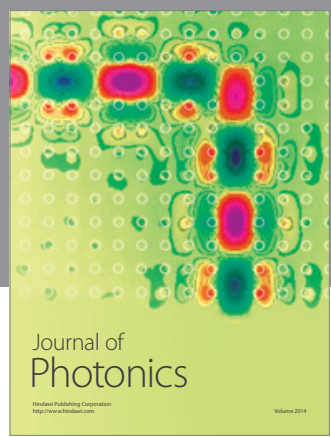

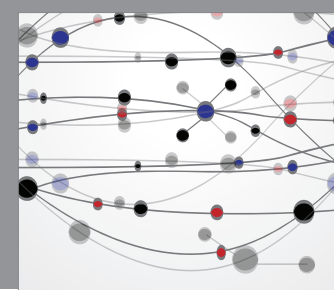

The Scientific World Journal

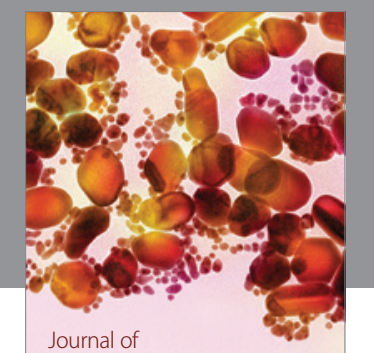

Soft Matter
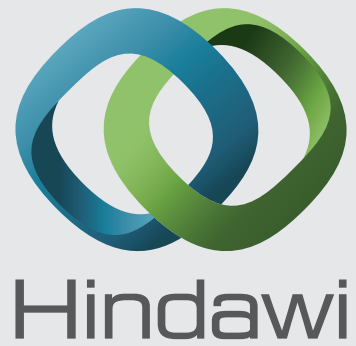

Submit your manuscripts at

http://www.hindawi.com
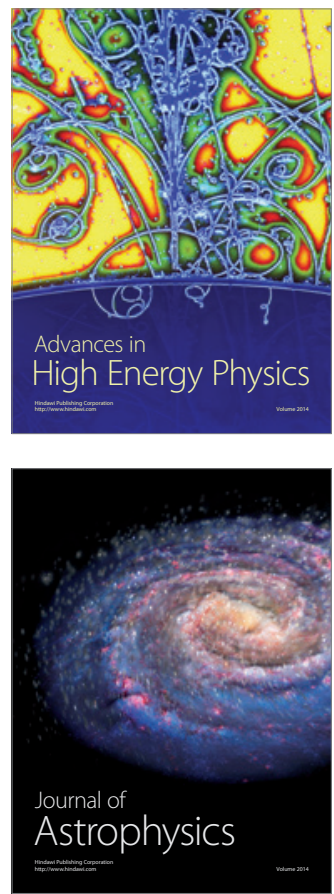
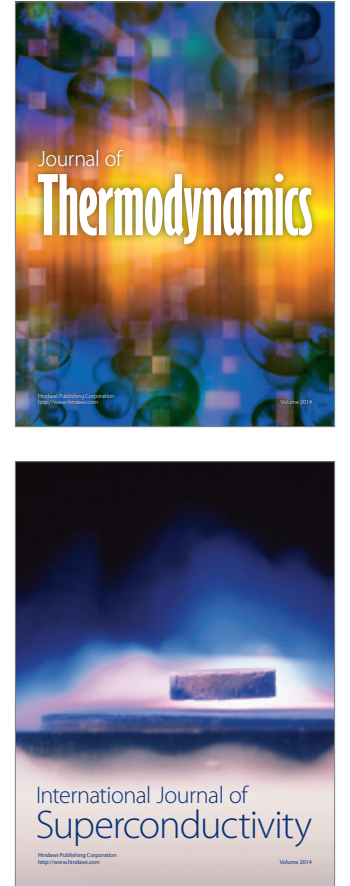
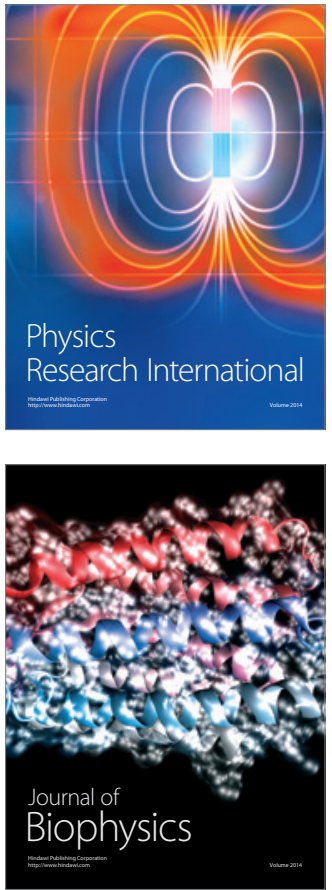
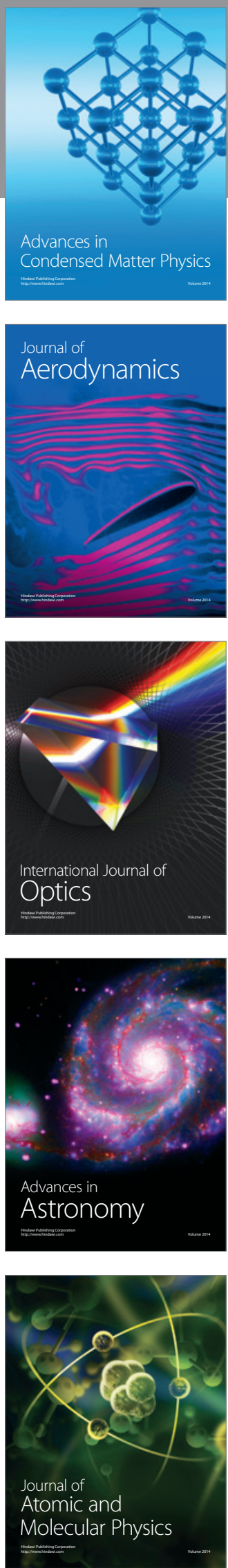